\title{
Medial Prefrontal Cortex controlling the immobility of rats in the forced swimming test: a
} systematic review and meta-analysis.

Domingues, K. ${ }^{1,3}$, Melleu, F. F. ${ }^{2}$, Lino de Oliveira, C. ${ }^{1,3}$

Afiliation: ${ }^{1}$ Department of Pharmacology, Center of Biological Sciences, Federal University of Santa Catarina - UFSC, Campus Trindade, 88040-900 Florianópolis, SC, Brazil. ${ }^{2}$ Department of Anatomy, Institute of Biomedical Sciences, University of São Paulo, 05508-000 São Paulo, SP, Brazil. ${ }^{3}$

Department of Physiological Sciences, Center of Biological Sciences, Federal University of Santa Catarina - UFSC, Campus Trindade, 88040-900 Florianópolis, SC, Brazil.

Corresponding Author: Cilene Lino de Oliveira, Departamento de Ciências Fisiológicas, Centro de Ciências Biológicas, Universidade Federal de Santa Catarina, Campus Universitário Trindade, 88049900 - Florianópolis - SC - Brazil.

Contact: cilene.lino@ufsc.br 


\section{Introduction}

The prefrontal cortex (PFC) and subdivisions may control cognitive and emotional functions through to afferent and efferent connections with cortical and subcortical areas. The PFC receives projections from visual and auditory cortices, intraparietal and posterior cingulate areas controlling the attentional processes, thalamic nuclei involved in working or long term memory, and also from sectors of the amygdala controlling emotional memory (Barbas, 2000; Petrides and Pandya, 2002). Regarding the afferent projections, the PFC connects with the premotor cortex and brainstem controlling head and body movements and with hypothalamic areas controlling visceral and behavioral responses to emotions (Barbas, 2000).

Patients with damaged ventromedial PFC (vmPFC) presented decision-making impairments (Bechara and Damasio, 2005; Bechara et al., 1994; Bechara et al., 2003; Bechara et al., 1997) and weak expression of emotions processed in subcortical regions, such as anxiety (Cunningham and Zelazo, 2007; Davidson, 2002; Dixon and Christoff, 2014; Haber and Behrens, 2014; Ochsner and Gross, 2005). Deficiencies in the PFC function has also been linked to the onset of affective disorders such as depression (Drevets et al., 2008; Farb et al., 2010; Greicius et al., 2007; Mayberg et al., 2005) or anxiety (Bishop et al., 2004; Chamberlain et al., 2008; Davidson, 2002; Goldin et al., 2009) and bipolar disorders (Blumberg et al., 2003; Blumberg et al., 1999; Dixon et al., 2017; Frye et al., 2007).

Treatments for affective or anxiety disorders also affect the function of PFC (Carey et al., 2004; Crane et al., 2017; Evans et al., 2009; George et al., 2000; Whalen et al., 2008). For example, depressed or anxious patients benefited from daily treatment of PFC with transcranial magnetic stimulation (TMS) for two weeks (GEORG et al., 2000). Besides, treatment with the antidepressant citalopram (a selective serotonin reuptake inhibitor, SSRI) for eight weeks resulted in deactivation of the anterior cingulate cortex $(\mathrm{aCg})$ in patients with anxiety disorders, although no pattern of cortical activation predicted response to subsequent pharmacotherapy (CAREY et al., 2004). In depressed patients, 
functional magnetic resonance imaging (fMRI) showed a task-induced activity of vmPFC and anterior cingulate cortex $(\mathrm{aCg})$ as a predictor to remission after treatment with escitalopram or reboxetine (Crane et al., 2017). Moreover, patients manifesting lower activity in vmPFC and aCg may better profit from antidepressant treatment than those with high activity in these areas (Crane et al., 2017), indicating that low activity of the PFC might be either cause or consequence of the antidepressant effect. Studies in laboratory animals may help to establish the directions of a putative cause-effect relationship between PFC and antidepressant treatment.

In animal models, PFC also seems to contribute to the control of the behavioral effects of antidepressants (Sartim et al., 2016; Slattery et al., 2011). The inhibition of medial PFC (mPFC) or infralimbic cortex (IL) in rats (Sartim et al., 2016; Slattery et al., 2011) reduced immobility time in the forced swimming test (FST), a predictive test for the action of antidepressants in laboratory rodents (Porsolt et al., 1977; Porsolt et al., 1978). Injection of the GABAA agonist muscimol into mPFC reduced immobility time of rats in the FST, which is considered an antidepressant-like effect (Slattery et al., 2011). The 5-HT 1 A agonist 8-OH-DPAT injected in the IL also produced an antidepressant-like effect (Sartim et al., 2016). However, other studies reported absence of antidepressant-like effects by inhibiting the prelimbic (PL) or aCg or vmPFC in rats tested in the FST (Li et al., 2012; Burgdorf et al., 2013; Chang et al., 2014). These incongruent findings preclude a final appraisal on the role of PFC on antidepressant-like effects in animal models indicating different roles for different subdivisions (Figure 1).

The forced swimming test is a behavioral test with a predictive value, that is, a decreased immobility time may suggest that a certain compound may have an antidepressant activity.

The first session, the pre-test, is used to induce the immobility behavior, also referred to as behavioral despair, which is similar to the learned helplessness. This is the best condition to assess antidepressant effects. 
It is the most used test to screen antidepressant compounds.

It is sensible to most of the drugs used as antidepressant in humans and can differentiate drugs that do not have antidepressant activity, such as benzodiazepines. Other tests that rely on spontaneous or conditioned behaviors do not express the same sensibility to differ between antidepressants and other psychoactive drugs.

However, recent discussions stablish the immobility behavior as being more adaptive in this context, being a way to conserve energy until better chances of escape are presented.

Still, the FST is a tool to investigate the neural substrate involved in antidepressant action and response.

To address the hypothesis of different contributions of discrete subregions of the PFC to the control of rat behavior in the FST, a review of the available literature was performed. For a non-biased vision of the bibliography and well-powered analysis, a systematic review of the scientific literature followed by a meta-analysis was conducted according to a pre-planned protocol (Hooijmans et al., 2014a). The keywords, inclusion and exclusion criteria were planned to select publications reporting studies aiming to stimulate or inhibit the PFC, or any of its sub-divisions, before the FST in rats. Every publication included in the analysis was quali- and quantitatively evaluated to create a synthesis of the literature able to provide a robust evidence on the role of PFC on antidepressant-like effects.
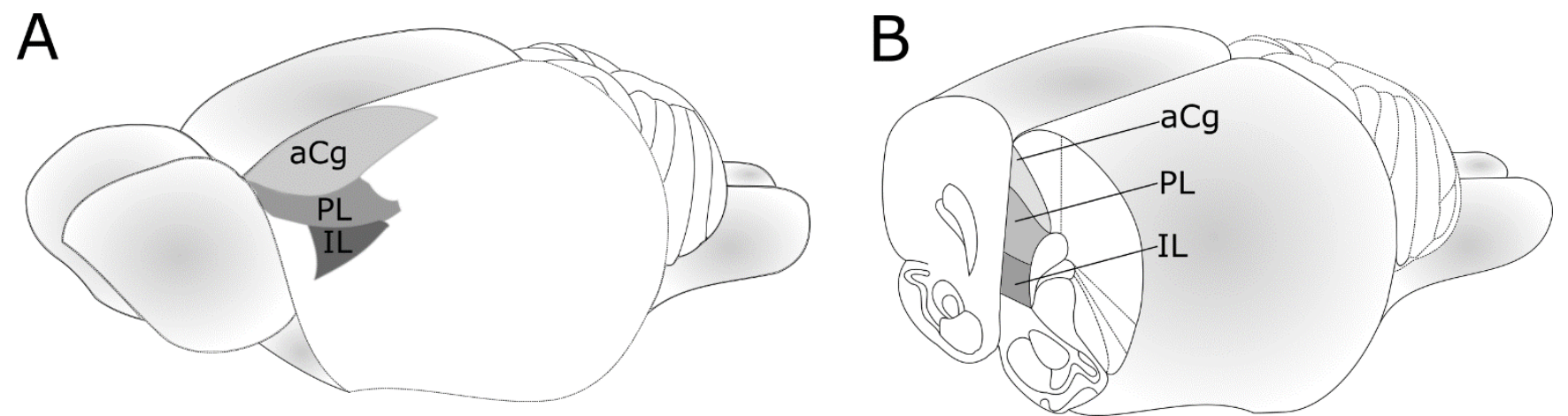

Legend for Figure 1. Anatomical subdivisions of the prefrontal cortex of the rat. A) Lateral view of the rat's brain. Shaded areas are showing the PFC and its subregions. B) Coronal section through rostral telencephalon. Shaded areas showing the PFC and subregions. Abbreviations: aCg: Anterior Cingulate cortex, PL: Prelimbic cortex, IL: Infralimbic cortex. 


\section{Methods}

\subsection{Systematic review:}

The protocol was developed based on the format of the platform Systematic Review Center for Laboratory animal Experimentation (SYRCLE). The full text of the protocol including search strategy, screening criteria and methods for the analysis was deposited at the platform Open Science Framework (OSF) (Domingues et al. 2018, https://osf.io/3wh6r/), i.e., decisions about search and analytics were taken beforehand. Briefly, the search in Medline was performed in 12/12/2019 using the advanced search of the platform PubMed (http://www.ncbi.nlm.nih.gov/pubmed) with Boolean operators, and the keywords were defined according to previous protocols (Ramos-Hryb et al., 2018), as well as the keywords of articles in the research field (Table 1). Predefined inclusion and exclusion criteria were applied in two rounds of screening to obtain relevant publications as follows: 1) analysis of the titles and abstracts and 2) full texts. Reviews, systematic reviews, and meta-analysis were excluded. Original articles were included in the review when published from 1977 until the day of the search since the FST protocol was first published in that year (Porsolt et al., 1977). Due to the previous evidence showing a role of the frontal cortex in the behaviour of rats submitted to the FST (Sartim et al., 2016; Slattery et al., 2011), only studies performed in rats were included independent of the experimental design. The interventions of interest were excitation or inhibition of the PFC or its subregions using local injections, electric stimulation or other local brain manipulation techniques (i.e. DBS). Interventions were classified as excitatory or inhibitory or unknown according to the definitions of the authors of each article. Subregions of the mPFC were classified as infralimbic cortex (IL), prelimbic cortex (PL), anterior cingulate cortex (ACg), medial prefrontal cortex (mPFC) or ventromedial prefrontal cortex (vmPFC), according to the definitions reported by the authors of each article. The primary outcome was the immobility of rats in the FST reported as time, frequency, scores. Studies using rats with comorbidities or receiving co-treatment or not presenting appropriated population, interventions or 
outcomes were excluded. Quality assessment of the included publications was performed by using the table adapted from Risk of bias tool of SYRCLE (Hooijmans et al., 2014b).

Table 1 - Search strategy and selection of publications:

\begin{tabular}{|c|c|c|}
\hline Domain & Keywords & Selection criteria \\
\hline Behavioural test & $\begin{array}{l}\text { forced swimming test OR forced } \\
\text { swimming tests OR forced } \\
\text { swimming test, fst OR fst OR forced } \\
\text { swim OR Porsolt test OR Porsolt } \\
\text { tests. }\end{array}$ & $\begin{array}{l}\text { Included studies published } \\
\text { after } 1977 \text { reporting time or } \\
\text { frequency or scores of } \\
\text { immobility in the FST. } \\
\text { Excluded studies that did not } \\
\text { evaluate immobility or } \\
\text { behaviour in the FST. }\end{array}$ \\
\hline Population & 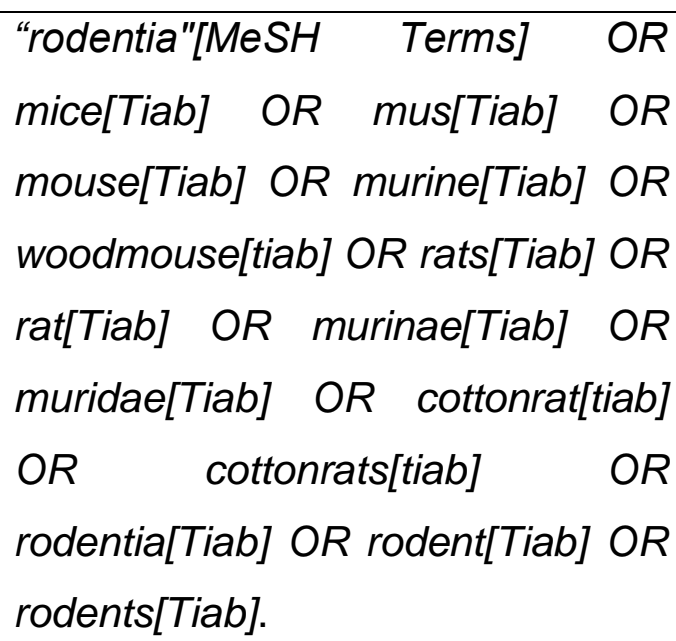 & $\begin{array}{l}\text { Included studies in healthy } \\
\text { rats. Excluded studies using } \\
\text { diseased rats (as in } \\
\text { experimental models of } \\
\text { pathologies) }\end{array}$ \\
\hline Brain region & $\begin{array}{l}\text { medial prefrontal cortex OR medial } \\
\text { pre frontal cortex OR medial PFC } \\
\text { OR mPFC OR infralimbic córtex OR } \\
\text { ventromedial pré-frontal cortex OR } \\
\text { ventromedial PFC OR vmPFC or } \\
\text { Cingulate cortex }\end{array}$ & $\begin{array}{l}\text { Included studies manipulating } \\
\text { the activity of the mPFC using } \\
\text { injections, electric stimulation, } \\
\text { etc before or during the } \\
\text { behavioural assessment in } \\
\text { the FST. Excluded studies } \\
\text { observing the activity of the } \\
\text { mPFC after systemic } \\
\text { treatment or behavioural } \\
\text { testing. }\end{array}$ \\
\hline
\end{tabular}




\section{Refazer pois nova busca :B}

Legend for Figure 2. Flowchart of the systematic review and meta-analysis

\subsection{Meta-analysis:}

For the meta-analysis (according to Domingues et al. 2018) the following parameters were extracted by KD (double-checked by FFM) from the included publications: mean, standard error, standard deviation of the primary outcome, sample size (number of animals per group; experimental or control). When available, data were extracted directly from the text or the graphical figures with a measurement ruler tool from Adobe Acrobat Reader®. When sample sizes were not clearly reported, for example, reporting only a range of the number of animals across different groups, the median of the sample size rounded down without decimals was used.

\subsection{Analysis of the overall data}

Data were meta-analyzed by random-effects model using a custom script (available in: https://osf.io/3wh6r/) written in R (http://www.r-project.org/) with the statistical package "Metafor" (free use and access, download available in http://www.metafor-project.org). Since diverse manipulations and anatomical regions were found in our systematic review could result in antagonic resuls, that is, the effect could either be reduction of increase in immobility, we chose this model of analysis because it permits two tails.

\subsection{Effect sizes calculation}

In brief, The calculation of effect sizes was performed using Hedges' g (Hedges, 1981), given by Equation (1):

$$
g=\frac{x_{1}-x_{2}}{S D}(1)
$$


Being, $x_{1}=$ mean of the experimental group; $x_{2}=$ mean of the control group; $\mathrm{SD}=$ combined standard deviation, which is given by Equation (2):

$$
S D=\sqrt{\frac{\left(n_{1}-1\right) X S D_{1}+\left(n_{2}-1\right) X S D_{2}^{2}}{n_{1}+n_{2}-2}}(2)
$$

Being, $\mathrm{n}_{1}=$ number of animals in the experimental group; $\mathrm{SD}_{1}{ }^{2}=$ Standard deviation of the experimental group squared; $\mathrm{n}_{2}=$ number of animals in the control group; $\mathrm{SD}_{2}{ }^{2}=$ standard deviation of the control group squared. It is important to note that the equations were organized in a way so that reductions in immobility in the FST, in other words, the "antidepressant-like effect", on experimental groups would yield negative effect sizes (experimental minus controls). This adaptation was done to improve data presentation since negative numbers will better imply the desired effect of the treatment (i.e. reduction of immobility). Concordantly, increased immobility would give positive g values interpreted as "stressor-like effect".

The magnitude of effect sizes were defined as "very small" (0.01-0.2); "small" (0.2-0.5); "medium" (0.5-0.8); "large" (0.8-1.2); "very large" (1.2-2); "huge" (>2) (Sawilowsky (2009). The estimated effect size was considered "statistically significant" when 95\% confidence interval (95\% CI) spare the null effect and "inconclusive" when 95\% CI overlap the null (Nakagawa and Cuthill (2007)

To further investigate the contribution of subgroups to the combined effect size of the overall model, a stratified meta-analysis was performed for each type of intervention (activation, inhibition, unknown) on each of the different sites, classified according to the nomenclature used by the author of the original study: IL, PL, aCg, mPFC (which includes IL + PL + acg), vmPFC (which includes IL + PL). 


\subsection{Heterogeneity analysis}

In these experimental settings, although some random variation is expected due to chance alone, heterogeneity may be caused by several factors of the studies due to (known or unknown) experimental design differences. Thus, we estimated the heterogeneity of the models using the $\mathrm{I}^{2}$ as an indicator of the percentage of the variance between studies (Higgins et al., 2003). The magnitude of heterogeneities was classified as "very low" (0-25\%); low (25-50\%); "moderate" (50-75\%); "high" (>75\%) (HIGGINS et al. (2003).

\subsection{Leave-one-out analysis}

This analysis was performed for all subgroups that presented high heterogeneity, however, only in one of the iterations of the IL subgroup was possible to reduce de value of heterogeneity, therefore only this result is presented.

\subsection{Sensitivity analysis}

A sensitivity analysis, using the leave-one-out method, consisted of repeating the calculations for Hedges' $\mathrm{g}$ without one of the studies in each iteration. This way, it was possible to assess the influence that each study had on both effect size and heterogeneity on the overall model

\subsection{Publication bias analysis}

The publication bias was assessed using the Trim and Fill analysis.

A symmetric funnel with no studies missing reveals the total absence of publication bias regarding this type of studies.

\section{Results}

\subsection{Systematic review}

The search in Pubmed retrieved 217 publications from which 181 were excluded from the analysis after two rounds of screening (Figure 2). Reasons for exclusion of publications were inappropriate population ( $\mathrm{n}=119$; 91 mice, 2 guinea pig, 1 human, 1 vole rat, 24 rats with comorbidity), intervention 
bioRxiv preprint doi: https://doi.org/10.1101/2021.04.27.441685; this version posted April 28, 2021. The copyright holder for this preprint (which

was not certified by peer review) is the author/funder, who has granted bioRxiv a license to display the preprint in perpetuity. It is made available under aCC-BY-NC-ND 4.0 International license.

( $\mathrm{n}=107 ; 45$ systemic treatment and 62 brain sites different of mPFC or subregions), outcome ( $\mathrm{n}=6$

without behavioural scoring) or type of publication ( $n=2$ reviews). The 39 publications included in the analysis reported 65 different studies in 1103 adult, male rats of different strains (Table 2). The list of references with complete bibliographic information may be found at (https://osf.io/wfsv6/). None of the studies included in the review reported either sample size calculations or randomization to group allocation while about a third of them reported blindness for outcome assessment $(n=14)$. About half of the studies did not mention randomization or blindness $(n=19)$. Few studies reported both randomization and blindness $(n=04)$ while one article declared no-blind assessment of the outcome (Table 2).

Table 2:

\begin{tabular}{|c|c|c|c|c|c|c|c|c|c|}
\hline \multicolumn{2}{|c|}{ Publication } & Population & \multicolumn{3}{|c|}{ Intervention } & \multicolumn{2}{|c|}{$n$} & \multicolumn{2}{|c|}{ Study design $^{\star \star \star \star}$} \\
\hline Author et al. & Year & Strain $^{*}$ & Type $^{\star \star}$ & Compound & Site $^{\star \star \star}$ & Cont. & Exp. & Random & Blind \\
\hline Natarajan & 2017 & SD & Excitatory & DOI & IL & 7 & 7 & unclear & Yes \\
\hline Kirkedal & 2017 & SD & Inhibitory & AA-5HT & $\mathrm{PL}$ & 18 & 18 & unclear & unclear \\
\hline \multirow[t]{4}{*}{ Sartim \# } & \multirow[t]{4}{*}{2017} & Wistar & Excitatory & Am251 & $\mathrm{PL}$ & 11 & 11 & \multirow[t]{4}{*}{ unclear } & \multirow[t]{4}{*}{ unclear } \\
\hline & & Wistar & Inhibitory & AA-5HT & $\mathrm{PL}$ & 10 & 10 & & \\
\hline & & Wistar & Inhibitory & URB597 & $\mathrm{PL}$ & 6 & 6 & & \\
\hline & & Wistar & Inhibitory & SB366791 & $\mathrm{PL}$ & 6 & 6 & & \\
\hline Xu \# & 2017 & SD & Unknown & LY294002 & $\mathrm{PL}$ & 8 & 8 & unclear & unclear \\
\hline Chen & 2016 & SD & Excitatory & Haloperidol & $\mathrm{PL}$ & 7 & 7 & Yes & Yes \\
\hline \multirow[t]{4}{*}{ Sartim \# } & \multirow[t]{4}{*}{2016} & Wistar & Inhibitory & CBD & $\mathrm{PL}$ & 8 & 8 & \multirow[t]{4}{*}{ Yes } & \multirow[t]{4}{*}{ Yes } \\
\hline & & Wistar & Inhibitory & CBD & $\mathrm{IL}$ & 8 & 8 & & \\
\hline & & Wistar & Inhibitory & 8-OH-DPAT & $\mathrm{PL}$ & 8 & 8 & & \\
\hline & & Wistar & Inhibitory & 8-OH-DPAT & $\mathrm{IL}$ & 8 & 8 & & \\
\hline \multirow[t]{2}{*}{ Navarria \# } & \multirow[t]{2}{*}{2015} & SD & Inhibitory & Scopolamine & $\mathrm{PL}$ & 8 & 8 & \multirow[t]{2}{*}{ unclear } & \multirow[t]{2}{*}{ unclear } \\
\hline & & SD & Inhibitory & Scopolamine & $\mathrm{IL}$ & 8 & 8 & & \\
\hline \multirow[t]{2}{*}{ Dwyer \# } & \multirow[t]{2}{*}{2015} & SD & Unknown & Virus & PFC & 9 & 9 & \multirow[t]{2}{*}{ Yes } & \multirow[t]{2}{*}{ Yes } \\
\hline & & SD & Unknown & Virus & $\mathrm{PL}$ & 8 & 8 & & \\
\hline Sun & 2015 & SD & Unknown & Cholesterol & $\mathrm{PL}$ & 8 & 8 & unclear & unclear \\
\hline \multirow[t]{2}{*}{ Pereira } & \multirow[t]{2}{*}{2015} & Wistar & Inhibitory & LY235959 & $\mathrm{PL}$ & 8 & 5 & unclear & unclear \\
\hline & & Wistar & Inhibitory & LY235959 & $\mathrm{IL}$ & 9 & 7 & & \\
\hline \multirow[t]{2}{*}{ Domin \# } & \multirow[t]{2}{*}{2014} & SD & Excitatory & L-AAA & mPFC & 11 & 11 & \multirow[t]{2}{*}{ unclear } & \multirow[t]{2}{*}{ unclear } \\
\hline & & SD & Inhibitory & MTEP & $\mathrm{mPFC}$ & 11 & 11 & & \\
\hline Chang & 2014 & SD & Inhibitory & Ibothenic acid & vmPFC & 10 & 24 & unclear & unclear \\
\hline
\end{tabular}


bioRxiv preprint doi: https://doi.org/10.1101/2021.04.27.441685; this version posted April 28, 2021. The copyright holder for this preprint (which was not certified by peer review) is the author/funder, who has granted bioRxiv a license to display the preprint in perpetuity. It is made available under aCC-BY-NC-ND 4.0 International license.

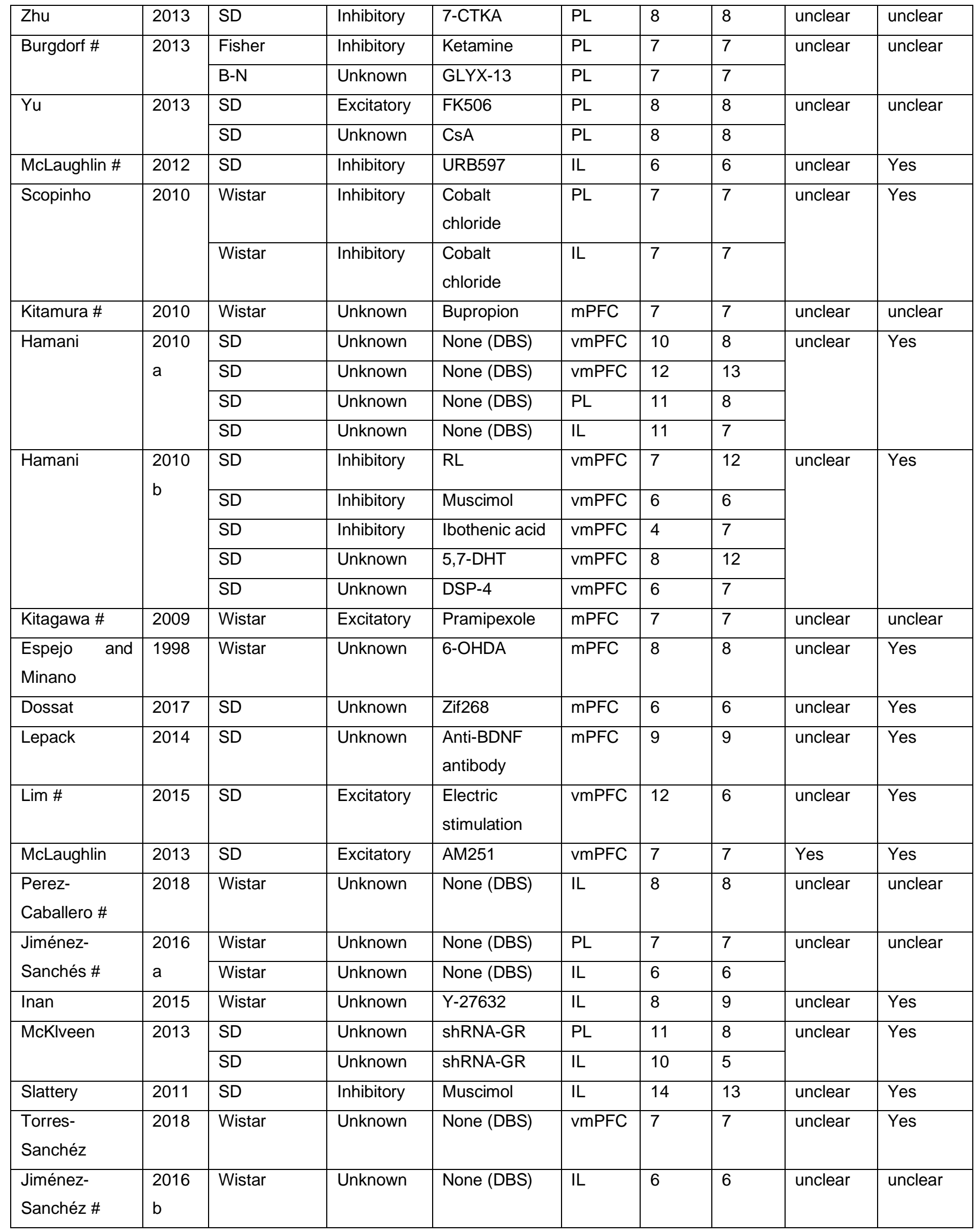




\begin{tabular}{|c|c|c|c|c|c|c|c|c|c|}
\hline \multirow[t]{4}{*}{ Lim } & \multirow[t]{4}{*}{2015} & SD & Unknown & $\begin{array}{ll}\text { None } & \text { (DBS } \\
\text { high) } & \end{array}$ & vmPFC & 14 & 10 & \multirow[t]{4}{*}{ unclear } & \multirow[t]{4}{*}{ unclear } \\
\hline & & SD & Unknown & $\begin{array}{l}\text { None } \quad \text { (DBS } \\
\text { high) }\end{array}$ & $\mathrm{aCg}$ & 14 & 8 & & \\
\hline & & SD & Unknown & $\begin{array}{l}\text { None } \quad \text { (DBS } \\
\text { low) }\end{array}$ & vmPFC & 14 & 10 & & \\
\hline & & SD & Unknown & $\begin{array}{ll}\text { None } & \text { (DBS } \\
\text { low) } & \end{array}$ & $\mathrm{aCg}$ & 14 & 8 & & \\
\hline Hamani & 2014 & SD & Unknown & None (DBS) & vmPFC & 14 & 9 & unclear & unclear \\
\hline Laver & 2014 & SD & Unknown & None (DBS) & vmPFC & 16 & 16 & unclear & No \\
\hline $\mathrm{Li}$ & 2012 & SD & Inhibitory & Kainic acid & $\mathrm{aCg}$ & 9 & 9 & unclear & Yes \\
\hline Bisserie & 2006 & SD & Inhibitory & Ibotenic acid & $\mathrm{aCg}$ & 11 & 11 & unclear & unclear \\
\hline
\end{tabular}

Abbreviations: aCg: anterior cingulate cortex B-N: Brown-Norway; DBS: deep brain stimulation; mPFC: medial prefrontal cortex, RL: Radiofrequency lesion; SD: Sprague-Dawley; \# indicates studies that did not report the exact number of animals per group; *all rats were male and adults; ${ }^{* *}$ types were defined by authors of primary studies; ${ }^{* * *}$ all studies reported bilateral injection or DBS, ${ }^{* * * *}$ no study reported sample size calculation.

\subsection{Meta-analysis}

Overall effect size ( $\mathrm{k}=63$ studies; Figure 3) was negative, i.e., in favor of the intervention, medium and significant with high heterogeneity (Hedges' $\mathrm{g}=-0.7656,95 \%$ CI: $-1.1,-0.43 ; \mathrm{p}<0.0001$; $\mathrm{I}^{2}=84,03 \%$ ). To estimate the publication bias, a funnel plot and Trim-and-fill analysis were performed. Trim-and-fill analysis suggested 12 studies missing in favor of controls/increased immobility in the FST (Figure 4), suggesting modest publication bias. The adjusted effect size was smaller than nonadjusted but still in favour of the intervention and statistically significant (Hedges' $\mathrm{g}=-0.3964 ; 95 \%$ CI: $-0.7577,-0.0352, \mathrm{p}<0.0315)$. The heterogeneity estimated by the adjusted model is higher than the original model $\left(\mathrm{I}^{2}=87.41 \%\right)$. In the stratified meta-analysis, heterogeneity remained high $\left(\mathrm{I}^{2}>75 \%\right)$ for most of the subgroups, except for "no heterogeneity" for the subgroups with a single study ("activation IL", “inhibition mPFC"); very-low for "unknown aCg"; low for "inhibition PL" medium heterogeneity for "unknown vmPFC". 
bioRxiv preprint doi: https://doi.org/10.1101/2021.04.27.441685; this version posted April 28, 2021. The copyright holder for this preprint (which was not certified by peer review) is the author/funder, who has granted bioRxiv a license to display the preprint in perpetuity. It is made available under aCC-BY-NC-ND 4.0 International license.

Author, Year (Experiment)

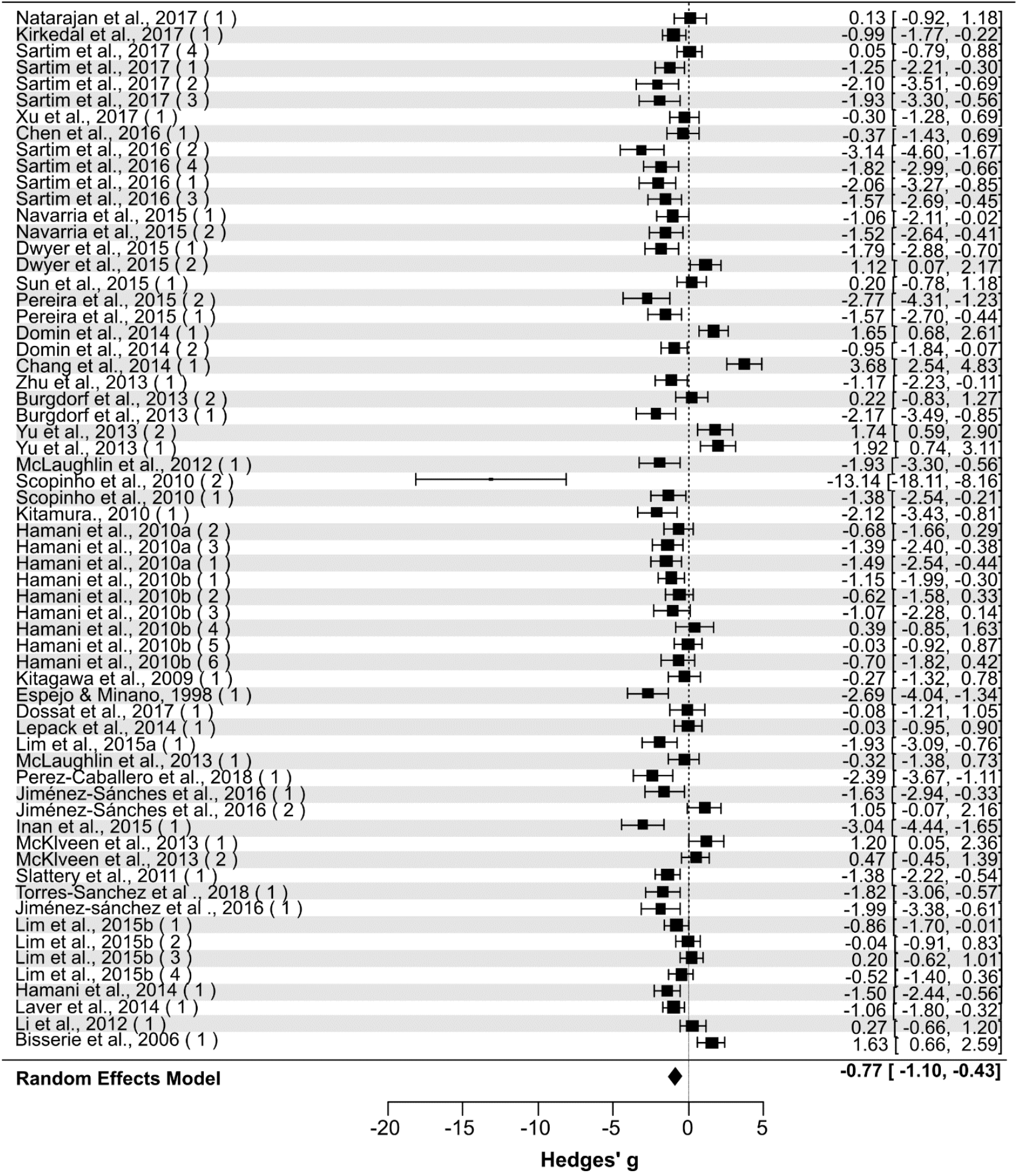

Legend for Figure 3. Forest Plot and results of the metanalysis with random-effects model. Showing the effects observed for each study (black squares) with its respective 95\% confidence intervals (horizontal lines, $\mathrm{Cl}$ ) and the effect of the total metanalysis (diamond). Sample sizes may be found in table 2. Symbols located at the left side of the dotted line (representing the null effect) indicate interventions reducing the immobility time in the FST (antidepressant-like effect). In contrast, those at the right side indicate intervention increasing immobility time (stressor-like effect). 
bioRxiv preprint doi: https://doi.org/10.1101/2021.04.27.441685; this version posted April 28, 2021. The copyright holder for this preprint (which was not certified by peer review) is the author/funder, who has granted bioRxiv a license to display the preprint in perpetuity. It is made available under aCC-BY-NC-ND 4.0 International license.

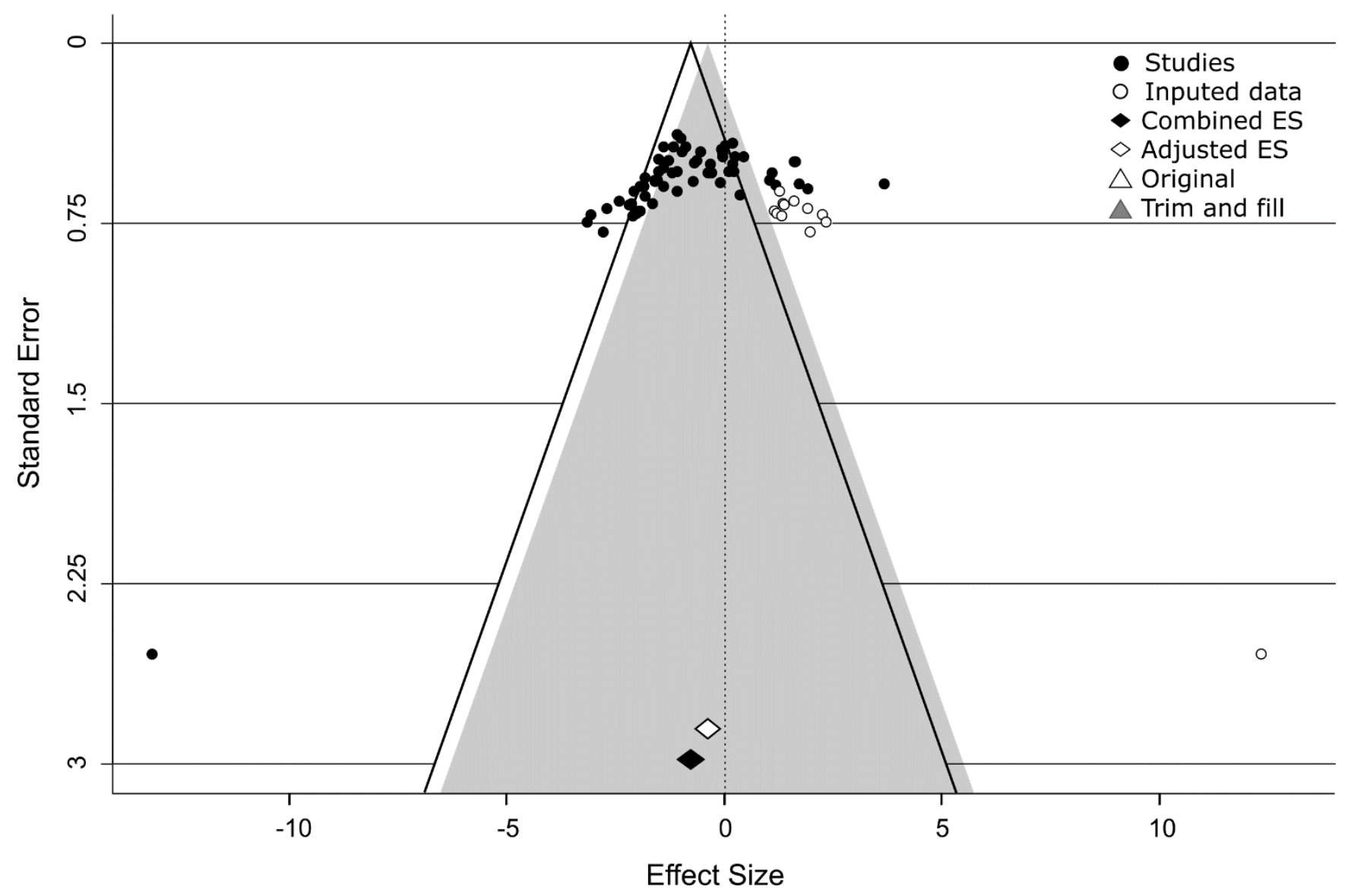

Figure 4. Funnel plot and Trim-and-fill analysis. Effect sizes (ES) calculated from the 63 studies (black dots) included in the original meta-analysis plotted against their errors yielded a slightly asymmetric funnel (black lines). Trim-and-fill analysis indicated 12 studies missing (blank circles) from original data in order to create symmetry in the funnel plot (shaded triangle). Non-adjusted combined effect size (black diamond) was towards the intervention side and statistically significant. Adjusted combined effect size (white diamond) was towards the intervention side, statistically significant but smaller than non-adjusted combined effect size. 


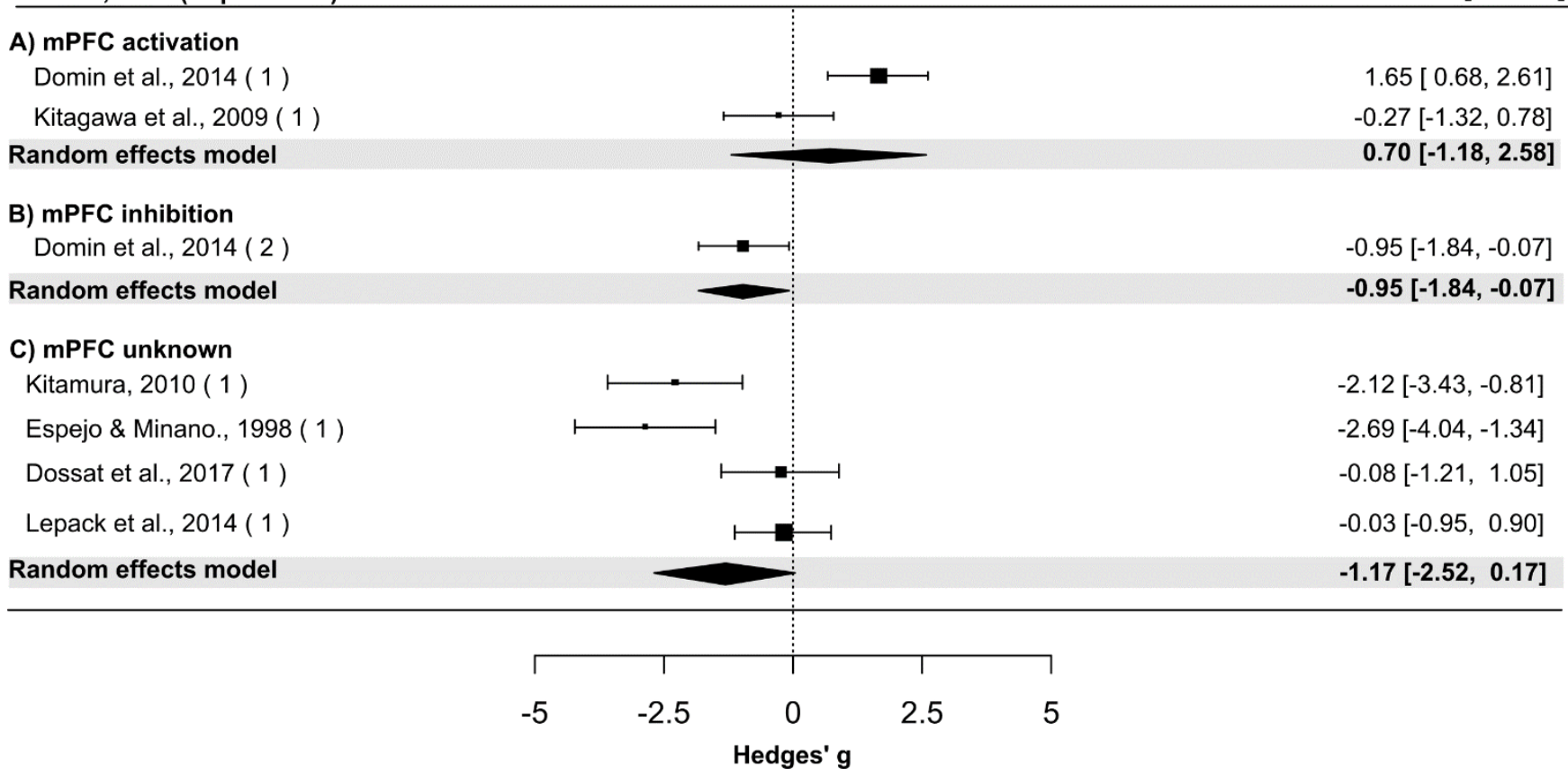

Figure 5. Forest Plot and metanalysis result of the subgroup mPFC (medial prefrontal cortex) with the randomeffects model. Showing the effects observed for each study (black squares) with their $95 \%$ confidence intervals (horizontal lines, $\mathrm{Cl}$ ) and metanalysis stratified by interventions (activation, inhibition, unknown, black diamonds). Sample sizes may be found in table 2. Symbols located at the left side of the dotted line (representing the null effect) indicate interventions reducing the immobility time in the FST (antidepressant-like effect). In contrast, those at the right side indicate intervention increasing immobility time (stressor-like effect).

For the subgroup "activation mPFC" (Figure $5 \mathrm{a} ; \mathrm{k}=2$ studies) there was a medium, nonsignificant increase of immobility with high heterogeneity (Hedges' $\mathrm{g}=0.6982 ; 95 \% \mathrm{CI}:-1.18,2.58$; $\mathrm{p}=0.4664 ; \mathrm{I}^{2}=85.52 \%$ ). For the subgroup “inhibition mPFC” (Figure $5 \mathrm{~b}, \mathrm{k}=1$ study), there was a large, significant reduction of immobility (Hedges' $g=-0.9531 ; 95 \% \mathrm{CI}:-1.84,-0.07 ; \mathrm{p}=0.0342$ ) with no heterogeneity since there was a single study. The subgroup of the "unknown mPFC" (Figure $5 \mathrm{c} ; \mathrm{k}=$ 4 studies) presented a very-large, non-significant reduction of immobility with high heterogeneity (Hedges' g = -1.17092; 95\% CI: $-2.52,0.17 ; \mathrm{p}=0.0881 ; \mathrm{I}^{2}=81.28 \%$ ). 
Author, Year (Experiment)

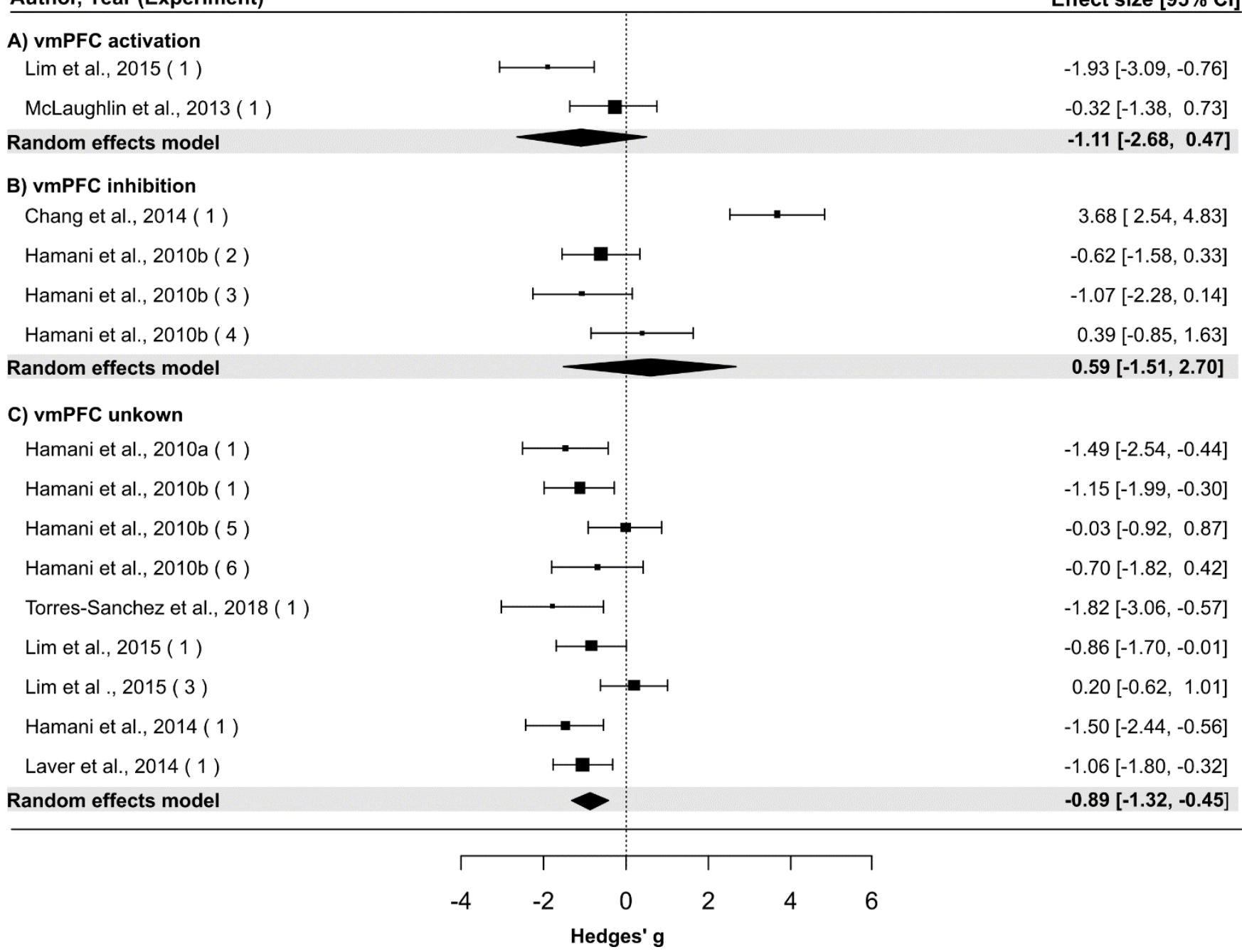

Figure 6. Forest Plot and metanalysis result of the subgroup vmPFC (ventral medial prefrontal cortex) with randomeffects model. Showing the effects observed for each study (black squares) with their $95 \%$ confidence intervals (horizontal lines, $\mathrm{Cl}$ ) and metanalysis stratified by interventions (activation, inhibition, unknown, black diamonds). Sample sizes may be found in table 2. Symbols located at the left side of the dotted line (representing the null effect) indicate interventions reducing the immobility time in the FST (antidepressant-like effect). In contrast, those at the right side indicate intervention increasing immobility time (stressor-like effect).

The subgroup "activation vmPFC" (Figure $6 \mathrm{a}, \mathrm{k}=2$ studies) presented a large, non-significant reduction of immobility with high heterogeneity (Hedges' $\mathrm{g}=-1.1057 ; 95 \% \mathrm{CI}:-2.68,0.47 ; \mathrm{p}=0.1682$; $\mathrm{I}^{2}=75.06 \%$ ). The subgroup "inhibition vmPFC" (Figure $6 \mathrm{~b}, \mathrm{k}=4$ studies), there was a medium, nonsignificant increase of immobility with high heterogeneity (Hedges' $\mathrm{g}=0.5907 ; 95 \% \mathrm{CI}:-1.51,2.70$; $\mathrm{p}=0.5824 ; \mathrm{I}^{2}=92.82 \%$ ). For the subgroup of the "unknown vmPFC" (Figure $6 \mathrm{c}, \mathrm{k}=9$ studies), there was a large, significant reduction of immobility with medium heterogeneity (Hedges' $g=-0.8859 ; 95 \%$ CI: $\left.-1.32,-0.45 ; \mathrm{p}<0.0001 ; \mathrm{I}^{2}=50.23 \%\right)$. 


\section{A) aCg activation}

N/A

Random effects model

B) $\mathbf{a C g}$ inhibition

Li et al ., 2012 ( 1 )

Bisserie et al ., 2006 ( 1 )

\section{Random effects model}

C) aCg unkown

Lim et al ., 2015 ( 2 )

Lim et al ., 2015 ( 4 )

N/A [N/A]
N/A [N/A]
$0.27[-0.66,1.20]$
$1.63[0.66,2.59]$
$0.94[-0.38,2.27]$
$-0.04[-0.91,0.83]$
$-0.52[-1.40,0.36]$
$-0.28[-0.90,0.34]$

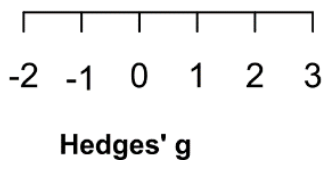

Figure 7. Forest Plot and metanalysis result of the subgroup aCg (anterior cingulate cortex) with random-effects model. Showing the effects observed for each study (black squares) with their $95 \%$ confidence intervals (horizontal lines, $\mathrm{Cl}$ ) and metanalysis stratified by interventions (activation, inhibition, unknown, black diamonds). Sample sizes may be found in table 2. Symbols located at the left side of the dotted line (representing the null effect) indicate interventions reducing the immobility time in the FST (antidepressant-like effect). In contrast, those at the right side indicate intervention increasing immobility time (stressor-like effect).

There were no cases in the subgroup "activation aCg" (Figure 7 a). The subgroup "inhibition aCg" (Figure $7 \mathrm{~b} ; \mathrm{k}=2$ studies) presented a large, non-significant increase of immobility with high heterogeneity (Hedges' $\mathrm{g}=0.9445 ; 95 \% \mathrm{CI}:-0.38,2.27 ; \mathrm{p}=0.1636 ; \mathrm{I}^{2}=74.63 \%$ ). For the subgroup "unknown aCg" (Figure $7 \mathrm{c}, \mathrm{k}=2$ studies), there was a small, non-significant reduction of immobility with null heterogeneity (Hedges' $g=-0.2774 ; 95 \% \mathrm{CI}:-0.90,0.34 ; \mathrm{p}=0.3797 ; \mathrm{I}^{2}=0 \%$ ). 
Author, Year (Experiment)

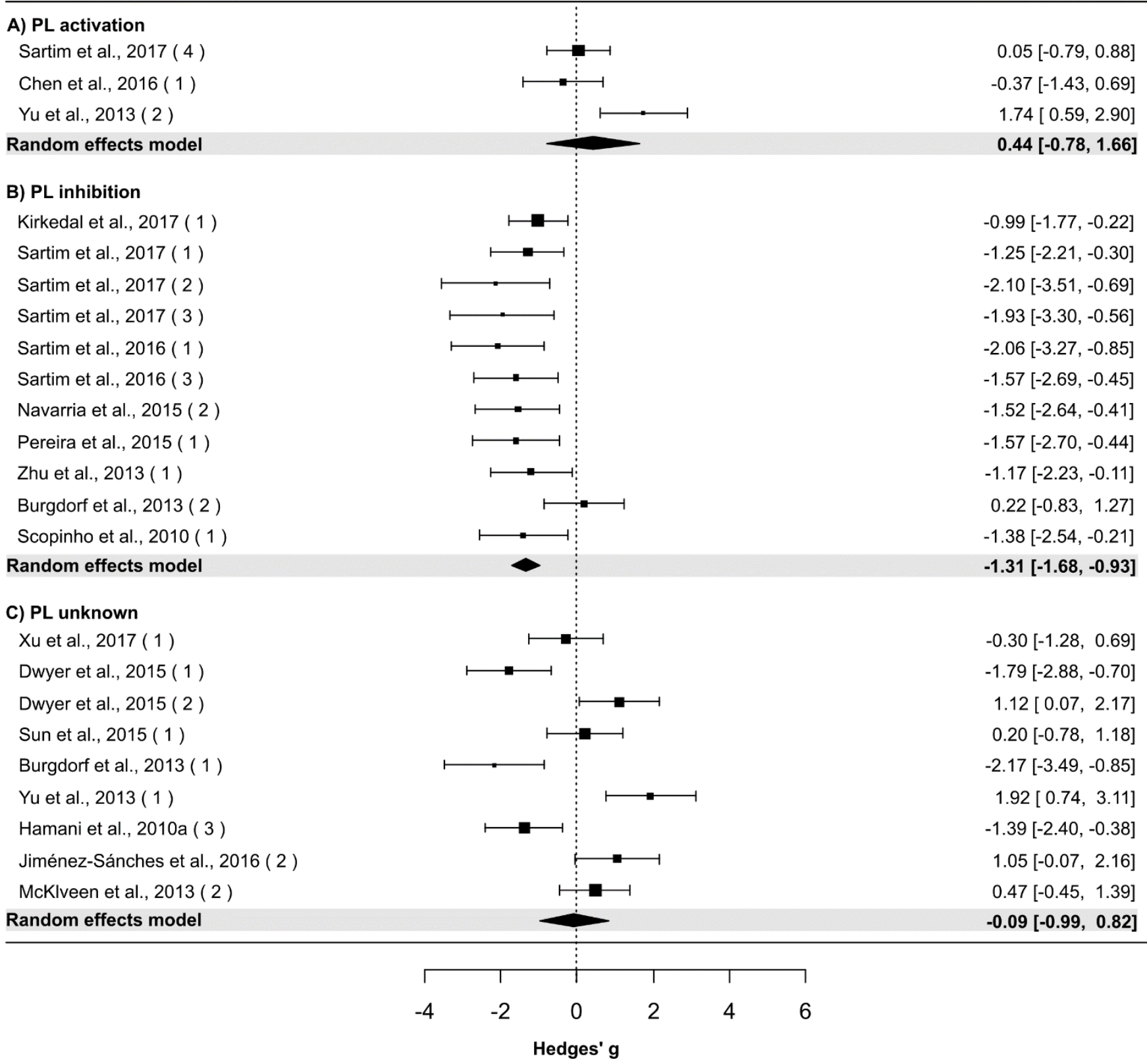

Figure 8. Forest Plot and metanalysis result of the subgroup PL (pre limbic cortex) with random-effects model. Showing the effects observed for each study (black squares) with their $95 \%$ confidence intervals (horizontal lines, $\mathrm{Cl}$ ) and metanalysis stratified by interventions (activation, inhibition, unknown, black diamonds). Sample sizes may be found in table 2. Symbols located at the left side of the dotted line (representing the null effect) indicate interventions reducing the immobility time in the FST (antidepressant-like effect). In contrast, those at the right side indicate intervention increasing immobility time (stressor-like effect).

For the subgroup "activation PL" (Figure $8 \mathrm{a} ; \mathrm{k}=3$ studies), there was a medium, nonsignificant increase of immobility with high heterogeneity (Hedges' $\mathrm{g}=0.4404$; 95\% CI: $-0.78,1.76$, $\mathrm{p}=0.4786 ; \mathrm{I}^{2}=77.12 \%$ ). For the subgroup “inhibition PL" (Figure $8 \mathrm{~b} ; \mathrm{k}=11$ studies), there was a 
very large, significant reduction of immobility with low heterogeneity (Hedges' $\mathrm{g}=-1.3091$; 95\% CI: 1.68, -0.93; $\mathrm{p}<0.0001 ; \mathrm{I}^{2}=22.67 \%$ ). For the subgroup "unknown PL" (Figure $8 \mathrm{c} ; \mathrm{k}=9$ studies), there was a very small, non-significant reduction of immobility with high heterogeneity (Hedges' $g=$ -

0.0883; 95\% CI: -0.99, 0.82, p=0.8484; $\left.\mathrm{I}^{2}=84.68 \%\right)$.

Author, Year (Experiment)

A) IL activation

Natarajan et al., 2017 ( 1 )

Random effects model

B) IL inhibition

Sartim et al., 2016 ( 2 )

Sartim et al., 2016 ( 4 )

Navarria et al., 2015 ( 1 )

Pereira et al ., 2015 ( 2 )

McLaughlin et al., 2012 ( 1 )

Scopinho et al., 2010 ( 2 )

Slattery et al., 2011 ( 1 )

Random effects model

C) IL Unkown

Hamani et al., 2010a ( 2 )

Perez-Caballero et al., 2018 ( 1 )

Jiménez-Sánches et a ., 2016a ( 1 )

Inan et al., 2015 ( 1 )

McKlveen et al., 2013 ( 1 )

Jiménez-Sánches et a ., 2016b ( 1 )

Random effects model
Effect size $[95 \% \mathrm{Cl}]$

$0.13[-0.92,1.18]$

$0.13[-0.92,1.18]$

-3.14 [ $-4.60,-1.67]$

$-1.82[-2.99,-0.66]$

-1.06 [ $-2.11,-0.02$ ]

-2.77 [ $-4.31,-1.23$ ]

$-1.93[-3.30,-0.56]$

$-13.14[-18.11,-8.16]$

-1.38 [ $-2.22,-0.54]$

$-2.89[-4.87,-0.92]$

$-0.68[-1.66,0.29]$

$-2.39[-3.67,-1.11]$

$-1.63[-2.94,-0.33]$

$-3.04[-4.44,-1.65]$

$1.20[0.05,2.36]$

$-1.99[-3.38,-0.61]$

$-1.39[-2.60,-0.17]$

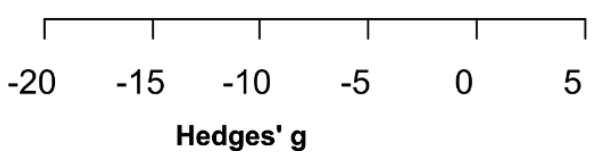

Figure 9. Forest Plot and metanalysis result of the subgroup IL (infra limbic cortex) with random-effects model. Showing the effects observed for each study (black squares) with their 95\% confidence intervals (horizontal lines, $\mathrm{Cl}$ ) and metanalysis stratified by interventions (activation, inhibition, unknown, black diamonds). Sample sizes may be found in table 2. Symbols located at the left side of the dotted line (representing the null effect) indicate interventions reducing the immobility time in the FST (antidepressant-like effect). In contrast, those at the right side indicate intervention increasing immobility time (stressor-like effect). 
Effect size

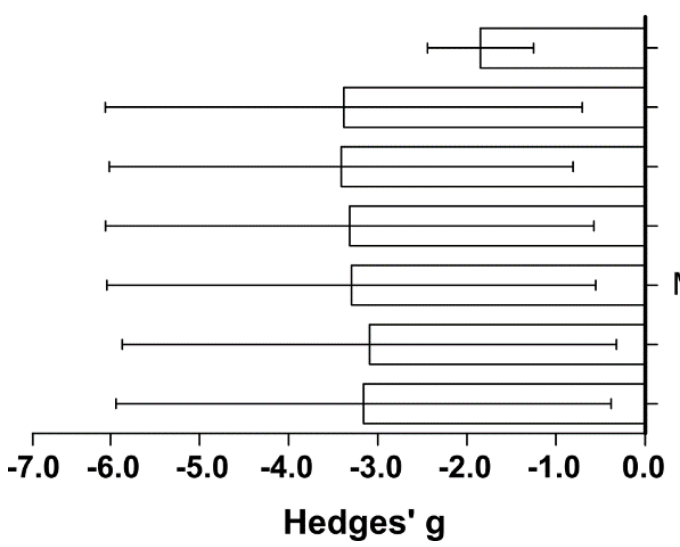

[Removed]

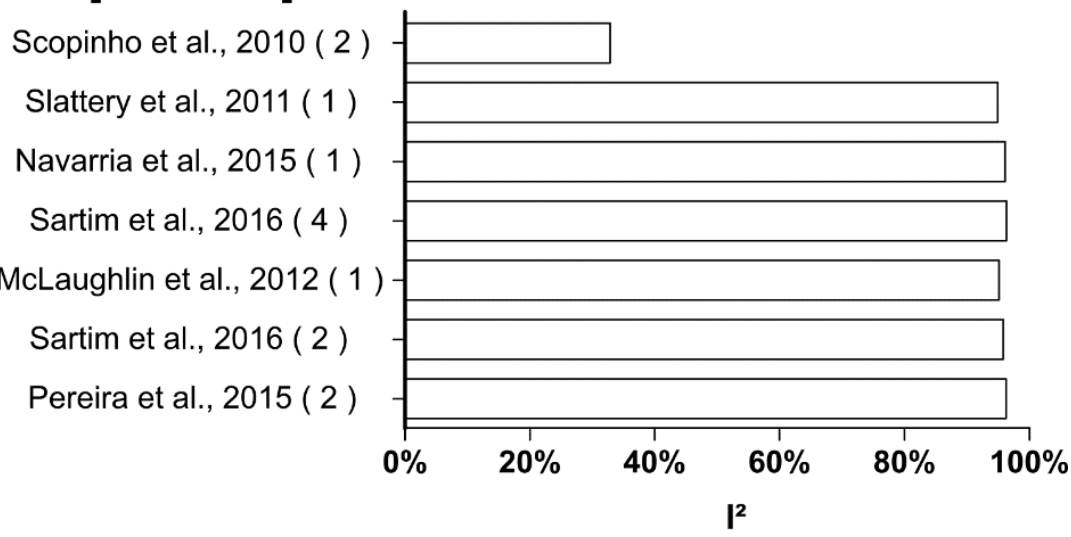

Figure 10. Sensitivity analysis "leave-one-out" of the subgroup "Infralimbic inhibition". The bars represent the combined effect size (Hedges' g, left side) or heterogeneity $\left(I^{2}\right.$, right side) calculated in the absence of the study mentioned in the respective line in the middle column.

The subgroup "activation IL" (Figure $9 \mathrm{a}, \mathrm{k}=1$ study) presented a small, no-significant increase of immobility (Hedges' $\mathrm{g}=0.1319 ; 95 \% \mathrm{CI}:-0.92,1.18 ; \mathrm{p}=0.8067$ ) with null heterogeneity since there was a single study in the subgroup. For the subgroup "inhibition IL" (Figure $9 \mathrm{~b}, \mathrm{k}=7$ studies), there was a huge and significant reduction of immobility with high heterogeneity (Hedges' $\mathrm{g}=-2.8942 ; 95 \%$ CI: $-4.87,-0.92 ; \mathrm{p}=0.0040 ; \mathrm{I}^{2}=93.49 \%$ ). Leave-one-out analysis showed heterogeneity remained high with removal of individual studies, except by excluding Scopinho et al. (2010) (Figure 10). Removal of Scopinho et al. (2010) reduced heterogeneity to low levels and CES to very large $\left(\mathrm{I}^{2}=\right.$ $32.8842 \%$; Hedges' $g=-1.8484$; 95\% CI: -2.44, -1.25; $\mathrm{p}<0.000001$; Figure 10). For the subgroup "unknown IL" (Figure 9 c, k = 6 studies), there was a large, significant reduction of immobility with high heterogeneity (Hedges' $g=-1.3856 ; 95 \%$ CI: -2.60, $-0.17, p=0.0256)\left(I^{2}=82,85 \%\right)$.

\section{Discussion}

This is the first quantitative review on the causal relationship between the intervention in the excitability of the mPFC and behaviour of rats in the FST. A systematic review and meta-analysis were performed to determine the direction, magnitude, significance, heterogeneity of effect sizes and the risk of biases in the field of research. The present data indicates that the combined effect size for the whole model was medium-sized, negative (i.e. antidepressant-like effect) and significant with high heterogeneity. The combined effect size, differently interpreted according to the research field, varied in magnitude when corrected by publication bias or stratified within types and sites of interventions. 
However, the lack of a consensus in the research field, very small or small effects may be considered less relevant than the medium, large or huge ones (Bezeau and Graves, 2001).

Combination of different types of bias may contribute to inflate the estimated effect size of an intervention distorting the appraisal of the efficacy (SENA et al, 2010; MACLEOD et al., 2015; RAMOS-HRYB et al 2018). Trim-and-fill analysis of the whole data set ( $\mathrm{k}=63)$ suggested 12 studies missing from the original model, indicating a possible publication bias towards the intervention. In fact, the adjusted effect size had a smaller magnitude and higher heterogeneity than the non-adjusted one, but still statistically significant. Risks of other types of bias (e.g. attrition and reporting, HOOIJMANS et al, 2014) were not appraised. Risk of selection, performance, and detection biases (HOOIJMANS et al, 2014) may not be discarded once that is unclear how randomization and blinding were used in most the publications, contributing to inflating the estimated effect size.

Conversely, subgroups of studies reporting effect sizes against the intervention or with small magnitude may deflate the combined effect size spuriously (LINO DE OLIVEIRA et al., 2020). Indeed, stratification of data by type of intervention and subregion of the mPFC yield antidepressant-like, statistically significant effects considered large, very large or even huge with the inhibition of the IL, PL or mPFC. In contrast, interventions that potentially increased neural activity of a given subregion of the PFC showed non-significant and predominantly positive (stressor-like effect) effect sizes, except for vmPFC in which a negative, albeit the non-significant effect was observed. Interestingly, interventions with unknown effects on the neural activity, had neglectable effects when applied to PL and aCg while prominent antidepressant-like effect when applied to IL, vmPFC or mPFC. However, none of the effects were statistically significant.

The huge magnitude of the effect sizes of inhibiting the IL suggested a higher contribution of this region to the control of rat immobility in the FST when compared to the large and very large magnitudes of inhibiting mPFC or PL, respectively. Further leave-one-out analysis of data suggests that the compound used to inhibit the IL may play a role in the magnitude of the effect size. Exclusion of Scopinho et al. (2010), a study using cobalt chloride to inhibit the IL with an effect size 5 times larger than the combined one, reduced the effect size and of the IL inhibition to values closer to, but still higher than, inhibition of PL. Cobalt chloride may cause more substantial effects since it is expected a total inhibition of a region, with a fast effect and recovery when compared to neuropharmacological inhibitions (Kretz, 1984). The hierarchical classification of the effect sizes, based on their magnitudes, could indicate a decrescent order of importance to IL, PL and mPFC in the antidepressant-like effects in rats in the FST. These last speculations require further research. 
The leave-one-out analysis also showed that the exclusion of an outlier study greatly decreased the heterogeneity of the subgroup "IL inhibition". In the remaining subgroups, null, very low, low or medium levels of heterogeneity varied with different types of intervention, subregion and number of studies examined. Null heterogeneity was observed when a single study was examined $(\mathrm{k}=1)$ impairing a meta-analysis and heterogeneity calculations such as "activation IL" "inhibition mPFC" but also in the subgroup "unknown ACg" with k=2 studies. In the meta-analysis for "unknown vmPFC" $(\mathrm{k}=9$ studies) heterogeneity was considered medium. The heterogeneity was low in the subgroup "inhibition of PL" ( $\mathrm{k}=11$ studies). Subgroups vmPFC and mPFC presented high heterogeneity $\left(\mathrm{I}^{2}>75 \%\right)$ similar to the overall heterogeneity. Magnitudes of heterogeneity represent the total amount of explained and unexplained variability due to known or unknown differences within experimental settings, here estimated as the percentage of variance between studies (Higgins et al., 2003). Fall in the levels of heterogeneity from the overall to subgroups, as observed for inhibition of IL, PL and mPFC or DBS in the vmPFC, suggest that type of intervention explained most of the variability. In contrast, high heterogeneity in the subgroups vmPFC and mPFC indicate an important contribution of unknowns to the observed heterogeneity. Different substances injected into the discrete cortical sites may explain the residual variability, but the myriad of compounds precluded an analysis of the subgroup.

Pharmacological interventions were compounds with diverse mechanisms of action, their inhibitory or excitatory actions on neural activity of a targeted brain region was presumed by authors interpretation since no study reported direct measures of it. Except for the ketamine (Burgdorf et al. (2013), all other presumably inhibitory compounds of the PL or IL had an antidepressant-like effect (agonists of the receptors $\mathrm{GABA}_{\mathrm{A}}$ (Muscimol: Slattery et al. (2011)), cannabinoids $\mathrm{CB}_{1}$ and $\mathrm{CB}_{2}$ (CBD: Sartim et al. (2016)), serotonergic 5-HT $1 \mathrm{~A}$ (8-OH-DPAT: Sartim et al. (2016)); and antagonists of glutamate NMDA, mGlu 5 receptors (LY235959: Pereira et al. (2015); MTEP: Domin et al. (2014); 7CTKA: Zhu et al. (2013); Ketamine: Burgdorf et al. (2013)),. In contrast, putatively excitatory compounds such as agonists of serotoninergic 5-HT $2 \mathrm{~A} / \mathrm{C}$ receptors (DOI: Natarajan et al. (2017)), dopaminergic $\mathrm{D}_{2}, \mathrm{D}_{3}$ and $\mathrm{D}_{4}$ receptors (pramipexole: Kitagawa et al. (2009)), antagonist of dopaminergic $\mathrm{D}_{2}$ receptors (haloperidol: Chen et al. (2016)) and cannabinoid CB 1 (AM251: Sartim et al. (2016)) had neglectable effects on immobility time when injected into PL or IL. These data indicated an equally prominent role for the receptors $\mathrm{GABA}_{\mathrm{A}}, \mathrm{CB}_{1}, 5-\mathrm{HT}_{1 \mathrm{~A}}$ or NMDA and a less critical to the $\mathrm{D}_{2}, \mathrm{D}_{3}$ and $\mathrm{D}_{4}$ dopaminergic and 5-HT2A/C of IL or PL on the control of the immobility behaviour in the FST. However, no empirical data exist to support the last assertions. 
Studies in which DBS was applied towards any cortical site were assigned to the subgroup "unknown", in regard of the consequence to the neuronal activity of the targeted brain region. DBS and other interventions with unknown effects on cortical excitability, assigned to the subgroup "unknown", yielded a large, significant, antidepressant-like effect in the FST. The authors of the studies did not measure neural activity during or after the intervention nor speculated about it (Hamani et al., 2014; Hamani et al., 2010; Jiménez-Sánchez et al., 2015; Jiménez-Sánchez et al., 2016; Laver et al., 2014; Lim et al., 2015; Perez-Caballero et al., 2018; Torres-Sanchez et al., 2018). Similar to temporary $\left(\mathrm{CoCl}_{2}\right.$ : Scopinho et al. (2010); Ibotenic Acid: Chang et al. (2014)) or permanent inactivation (Kainic acid: Li et al. (2012); radiofrequency lesions most of the studies applying DBS towards the IL or PL yielded antidepressant-like effect in the FST indicating a possible inhibition of neural activity in these brain structures. This last supposition was likely to be the more prudent, considering that the mechanisms underlying DBS effects on nervous tissue are poorly understood, as well as its ramifications to the overall neuronal function of the target region or its afferent/efferent regions (Chiken and Nambu, 2016; McIntyre et al., 2004).

The heterogeneity in the overall meta-effect may also arise from the variability in the subdivisions of the mPFC that are targeted by the various interventions, or simply from the way the neuroanatomy of the region is approached in the different studies. In rats, the subregions of the mPFC have distinct cytoarchitectural and hodological characteristics (Burgos-Robles et al., 2013; Hoover and Vertes, 2011; Hurley et al., 1991; Vertes, 2004). Thus, differences in function regarding behavioural control are to be expected. Studies that utilized inhibition protocols that encompassed large regions of the PFC yielded inconclusive results (vmPFC) or small effect sizes (mPFC). These inconclusive results may occur due to the lack of spatial resolution of the intervention site since inhibiting multiple subregions at the same time could lead to antagonistic behavioural outcomes.

In summary, the present systematic review and meta-analysis indicate that the inhibition of either IL or PL was necessary and sufficient to produce an antidepressant-like effect in male rats in the FST. Moreover, data from the literature suggest that the inhibition of the IL or PL regions mediated by the combination of different systems may be a mechanism underlying the effect of antidepressant drugs.

\section{Declarations of interest}

The author declares no conflict of interests. 
bioRxiv preprint doi: https://doi.org/10.1101/2021.04.27.441685; this version posted April 28, 2021. The copyright holder for this preprint (which

was not certified by peer review) is the author/funder, who has granted bioRxiv a license to display the preprint in perpetuity. It is made available under aCC-BY-NC-ND 4.0 International license.

\section{Acknowledgements:}

Karolina Domingues was supported by Conselho Nacional de Desenvolvimento Científico e

Tecnológico (140007/2016-4), Brazil. Fernando F.F.M was supported by Post-doctoral fellowship grant \#2018/25857-5, São Paulo Research Foundation (FAPESP), Brazil. This study was financed in part by the Coordenação de Aperfeiçoamento de Pessoal de Nível Superior - Brasil (CAPES) - Finance Code 001". 


\section{References}

Barbas, H., 2000. Connections underlying the synthesis of cognition, memory, and emotion in primate prefrontal cortices. Brain research bulletin 52, 319-330.

Bechara, A., Damasio, A.R., 2005. The somatic marker hypothesis: A neural theory of economic decision. Games and economic behavior 52, 336-372.

Bechara, A., Damasio, A.R., Damasio, H., Anderson, S.W., 1994. Insensitivity to future consequences following damage to human prefrontal cortex. Cognition 50, 7-15.

Bechara, A., Damasio, H., Damasio, A.R., 2003. Role of the amygdala in decision-making. Annals of the New York Academy of Sciences 985, 356-369.

Bechara, A., Damasio, H., Tranel, D., Damasio, A.R., 1997. Deciding advantageously before knowing the advantageous strategy. Science 275, 1293-1295.

Bezeau, S., Graves, R., 2001. Statistical power and effect sizes of clinical neuropsychology research. Journal of clinical and experimental neuropsychology 23, 399-406.

Bishop, S., Duncan, J., Brett, M., Lawrence, A.D., 2004. Prefrontal cortical function and anxiety: controlling attention to threat-related stimuli. Nature neuroscience 7, 184.

Blumberg, H.P., Leung, H.-C., Skudlarski, P., Lacadie, C.M., Fredericks, C.A., Harris, B.C., Charney, D.S., Gore, J.C., Krystal, J.H., Peterson, B.S., 2003. A functional magnetic resonance imaging study of bipolar disorder: state-and trait-related dysfunction in ventral prefrontal cortices. Archives of general psychiatry 60, 601-609.

Blumberg, H.P., Stern, E., Ricketts, S., Martinez, D., de Asis, J., White, T., Epstein, J., Isenberg, N., McBride, P.A., Kemperman, I., 1999. Rostral and orbital prefrontal cortex dysfunction in the manic state of bipolar disorder. American Journal of Psychiatry 156, 1986-1988.

Burgdorf, J., Zhang, X.-I., Nicholson, K.L., Balster, R.L., Leander, J.D., Stanton, P.K., Gross, A.L., Kroes, R.A., Moskal, J.R., 2013. GLYX-13, a NMDA receptor glycine-site functional partial agonist, induces antidepressant-like effects without ketamine-like side effects. Neuropsychopharmacology 38, 729.

Burgos-Robles, A., Bravo-Rivera, H., Quirk, G.J., 2013. Prelimbic and infralimbic neurons signal distinct aspects of appetitive instrumental behavior. PloS one 8, e57575.

Carey, P.D., Warwick, J., Niehaus, D.J., Van der Linden, G., Van Heerden, B.B., Harvey, B.H., Seedat, S., Stein, D.J., 2004. Single photon emission computed tomography (SPECT) of anxiety disorders before and after treatment with citalopram. BMC psychiatry 4, 30.

Chamberlain, S.R., Menzies, L., Hampshire, A., Suckling, J., Fineberg, N.A., del Campo, N., Aitken, M., Craig, K., Owen, A.M., Bullmore, E.T., 2008. Orbitofrontal dysfunction in patients with obsessive-compulsive disorder and their unaffected relatives. Science 321, 421-422.

Chang, C.H., Chen, M.C., Qiu, M.H., Lu, J., 2014. Ventromedial prefrontal cortex regulates depressive-like behavior and rapid eye movement sleep in the rat. Neuropharmacology 86, 125-132.

Chen, C., Nakagawa, S., Kitaichi, Y., An, Y., Omiya, Y., Song, N., Koga, M., Kato, A., Inoue, T., Kusumi, I., 2016. The role of medial prefrontal corticosterone and dopamine in the antidepressant-like effect of exercise. Psychoneuroendocrinology 69, 1-9.

Chiken, S., Nambu, A., 2016. Mechanism of deep brain stimulation: inhibition, excitation, or disruption? The Neuroscientist 22, 313-322.

Crane, N.A., Jenkins, L.M., Bhaumik, R., Dion, C., Gowins, J.R., Mickey, B.J., Zubieta, J.-K., Langenecker, S.A., 2017. Multidimensional prediction of treatment response to antidepressants with cognitive control and functional MRI. Brain 140, 472-486.

Cunningham, W.A., Zelazo, P.D., 2007. Attitudes and evaluations: A social cognitive neuroscience perspective. Trends in cognitive sciences 11, 97-104.

Davidson, R.J., 2002. Anxiety and affective style: role of prefrontal cortex and amygdala. Biological psychiatry 51, 68-80.

Dixon, M.L., Christoff, K., 2014. The lateral prefrontal cortex and complex value-based learning and decision making. Neuroscience \& Biobehavioral Reviews 45, 9-18. 
Dixon, M.L., Thiruchselvam, R., Todd, R., Christoff, K., 2017. Emotion and the prefrontal cortex: An integrative review. Psychological bulletin 143, 1033.

Domin, H., Szewczyk, B., Woźniak, M., Wawrzak-Wleciał, A., Śmiałowska, M., 2014. Antidepressant-like effect of the mGluR5 antagonist MTEP in an astroglial degeneration model of depression. Behavioural brain research 273, 23-33.

Drevets, W.C., Savitz, J., Trimble, M., 2008. The subgenual anterior cingulate cortex in mood disorders. CNS spectrums 13, 663.

Evans, K.C., Simon, N.M., Dougherty, D.D., Hoge, E.A., Worthington, J.J., Chow, C., Kaufman, R.E., Gold, A.L., Fischman, A.J., Pollack, M.H., 2009. A PET study of tiagabine treatment implicates ventral medial prefrontal cortex in generalized social anxiety disorder. Neuropsychopharmacology 34, 390-398.

Farb, N.A., Anderson, A.K., Mayberg, H., Bean, J., McKeon, D., Segal, Z.V., 2010. Minding one's emotions: mindfulness training alters the neural expression of sadness. Emotion 10, 25.

Frye, M.A., Watzl, J., Banakar, S., O'Neill, J., Mintz, J., Davanzo, P., Fischer, J., Chirichigno, J.W., Ventura, J., Elman, S., 2007. Increased anterior cingulate/medial prefrontal cortical glutamate and creatine in bipolar depression. Neuropsychopharmacology 32, 2490.

George, M.S., Nahas, Z., Molloy, M., Speer, A.M., Oliver, N.C., Li, X.-B., Arana, G.W., Risch, S.C., Ballenger, J.C., 2000. A controlled trial of daily left prefrontal cortex TMS for treating depression. Biological psychiatry 48, 962970.

Goldin, P.R., Manber, T., Hakimi, S., Canli, T., Gross, J.J., 2009. Neural bases of social anxiety disorder: emotional reactivity and cognitive regulation during social and physical threat. Archives of general psychiatry 66, 170-180. Greicius, M.D., Flores, B.H., Menon, V., Glover, G.H., Solvason, H.B., Kenna, H., Reiss, A.L., Schatzberg, A.F., 2007. Resting-state functional connectivity in major depression: abnormally increased contributions from subgenual cingulate cortex and thalamus. Biological psychiatry 62, 429-437.

Haber, S.N., Behrens, T.E., 2014. The neural network underlying incentive-based learning: implications for interpreting circuit disruptions in psychiatric disorders. Neuron 83, 1019-1039.

Hamani, C., Amorim, B.O., Wheeler, A.L., Diwan, M., Driesslein, K., Covolan, L., Butson, C.R., Nobrega, J.N., 2014. Deep brain stimulation in rats: different targets induce similar antidepressant-like effects but influence different circuits. Neurobiology of disease 71, 205-214.

Hamani, C., Diwan, M., Macedo, C.E., Brandão, M.L., Shumake, J., Gonzalez-Lima, F., Raymond, R., Lozano, A.M., Fletcher, P.J., Nobrega, J.N., 2010. Antidepressant-like effects of medial prefrontal cortex deep brain stimulation in rats. Biological psychiatry 67, 117-124.

Hedges, L.V., 1981. Distribution theory for Glass's estimator of effect size and related estimators. journal of Educational Statistics 6, 107-128.

Higgins, J.P., Thompson, S.G., Deeks, J.J., Altman, D.G., 2003. Measuring inconsistency in meta-analyses. BMJ: British Medical Journal 327, 557.

Hooijmans, C.R., IntHout, J., Ritskes-Hoitinga, M., Rovers, M.M., 2014a. Meta-analyses of animal studies: an introduction of a valuable instrument to further improve healthcare. ILAR journal 55, 418-426.

Hooijmans, C.R., Rovers, M.M., De Vries, R.B., Leenaars, M., Ritskes-Hoitinga, M., Langendam, M.W., $2014 b$. SYRCLE's risk of bias tool for animal studies. BMC medical research methodology 14, 43.

Hoover, W.B., Vertes, R.P., 2011. Projections of the medial orbital and ventral orbital cortex in the rat. Journal of Comparative Neurology 519, 3766-3801.

Hurley, K.M., Herbert, H., Moga, M.M., Saper, C.B., 1991. Efferent projections of the infralimbic cortex of the rat. Journal of Comparative Neurology 308, 249-276.

Jiménez-Sánchez, L., Castañé, A., Pérez-Caballero, L., Grifoll-Escoda, M., López-Gil, X., Campa, L., Galofré, M., Berrocoso, E., Adell, A., 2015. Activation of AMPA receptors mediates the antidepressant action of deep brain stimulation of the infralimbic prefrontal cortex. Cerebral Cortex 26, 2778-2789.

Jiménez-Sánchez, L., Linge, R., Campa, L., Valdizán, E.M., Pazos, Á., Díaz, Á., Adell, A., 2016. Behavioral, neurochemical and molecular changes after acute deep brain stimulation of the infralimbic prefrontal cortex. Neuropharmacology 108, 91-102. 
Kitagawa, K., Kitamura, Y., Miyazaki, T., Miyaoka, J., Kawasaki, H., Asanuma, M., Sendo, T., Gomita, Y., 2009. Effects of pramipexole on the duration of immobility during the forced swim test in normal and ACTH-treated rats. Naunyn-Schmiedeberg's archives of pharmacology 380, 59-66.

Kretz, R., 1984. Local cobalt injection: a method to discriminate presynaptic axonal from postsynaptic neuronal activity. Journal of neuroscience methods 11, 129-135.

Laver, B., Diwan, M., Nobrega, J.N., Hamani, C., 2014. Augmentative therapies do not potentiate the antidepressant-like effects of deep brain stimulation in rats. Journal of affective disorders 161, 87-90.

Li, F., Li, M., Cao, W., Xu, Y., Luo, Y., Zhong, X., Zhang, J., Dai, R., Zhou, X.-F., Li, Z., 2012. Anterior cingulate cortical lesion attenuates food foraging in rats. Brain research bulletin 88, 602-608.

Lim, L.W., Janssen, M.L., Kocabicak, E., Temel, Y., 2015. The antidepressant effects of ventromedial prefrontal cortex stimulation is associated with neural activation in the medial part of the subthalamic nucleus. Behavioural brain research 279, 17-21.

Mayberg, H.S., Lozano, A.M., Voon, V., McNeely, H.E., Seminowicz, D., Hamani, C., Schwalb, J.M., Kennedy, S.H., 2005. Deep brain stimulation for treatment-resistant depression. Neuron 45, 651-660.

McIntyre, C.C., Savasta, M., Kerkerian-Le Goff, L., Vitek, J.L., 2004. Uncovering the mechanism (s) of action of deep brain stimulation: activation, inhibition, or both. Clinical neurophysiology 115, 1239-1248.

Nakagawa, S., Cuthill, I.C., 2007. Effect size, confidence interval and statistical significance: a practical guide for biologists. Biological reviews 82, 591-605.

Natarajan, R., Forrester, L., Chiaia, N., Yamamoto, B.K., 2017. Chronic Stress-induced Behavioral Changes Associated with Subregion Selective Serotonin Cell Death in the Dorsal Raphe. Journal of Neuroscience, 37813716.

Ochsner, K.N., Gross, J.J., 2005. The cognitive control of emotion. Trends in cognitive sciences 9, 242-249.

Pereira, V.S., Romano, A., Wegener, G., Joca, S.R., 2015. Antidepressant-like effects induced by NMDA receptor blockade and NO synthesis inhibition in the ventral medial prefrontal cortex of rats exposed to the forced swim test. Psychopharmacology 232, 2263-2273.

Perez-Caballero, L., Soto-Montenegro, M., Hidalgo-Figueroa, M., Mico, J., Desco, M., Berrocoso, E., 2018. Deep brain stimulation electrode insertion and depression: Patterns of activity and modulation by analgesics. Brain stimulation.

Petrides, M., Pandya, D., 2002. Comparative cytoarchitectonic analysis of the human and the macaque ventrolateral prefrontal cortex and corticocortical connection patterns in the monkey. European Journal of Neuroscience 16, 291-310.

Porsolt, R., Le Pichon, M., Jalfre, M., 1977. Depression: a new animal model sensitive to antidepressant treatments. Nature 266, 730.

Porsolt, R.D., Anton, G., Blavet, N., Jalfre, M., 1978. Behavioural despair in rats: a new model sensitive to antidepressant treatments. European journal of pharmacology 47, 379-391.

Ramos-Hryb, A.B., Harris, C., Aighewi, O., Lino-de-Oliveira, C., 2018. How would publication bias distort the estimated effect size of prototypic antidepressants in the forced swim test? Neuroscience \& Biobehavioral Reviews.

Sartim, A., Guimarães, F., Joca, S., 2016. Antidepressant-like effect of cannabidiol injection into the ventral medial prefrontal cortex-Possible involvement of 5-HT1A and CB1 receptors. Behavioural brain research 303, 218-227. Sawilowsky, S.S., 2009. New effect size rules of thumb. Journal of Modern Applied Statistical Methods 8, 26.

Scopinho, A.A., Scopinho, M., Lisboa, S.F., de Aguiar Correa, F.M., Guimarães, F.S., Joca, S.R.L., 2010. Acute reversible inactivation of the ventral medial prefrontal cortex induces antidepressant-like effects in rats. Behavioural brain research 214, 437-442.

Slattery, D.A., Neumann, I.D., Cryan, J.F., 2011. Transient inactivation of the infralimbic cortex induces antidepressant-like effects in the rat. Journal of Psychopharmacology 25, 1295-1303.

Torres-Sanchez, S., Perez-Caballero, L., Mico, J.A., Celada, P., Berrocoso, E., 2018. Effect of Deep Brain Stimulation of the ventromedial prefrontal cortex on the noradrenergic system in rats. Brain stimulation 11, 222-230.

Vertes, R.P., 2004. Differential projections of the infralimbic and prelimbic cortex in the rat. Synapse 51, 32-58. 
bioRxiv preprint doi: https://doi.org/10.1101/2021.04.27.441685; this version posted April 28, 2021. The copyright holder for this preprint (which

was not certified by peer review) is the author/funder, who has granted bioRxiv a license to display the preprint in perpetuity. It is made available under aCC-BY-NC-ND 4.0 International license.

Whalen, P.J., Johnstone, T., Somerville, L.H., Nitschke, J.B., Polis, S., Alexander, A.L., Davidson, R.J., Kalin, N.H., 2008. A functional magnetic resonance imaging predictor of treatment response to venlafaxine in generalized anxiety disorder. Biological psychiatry 63, 858-863.

Zhu, W.-L., Wang, S.-J., Liu, M.-M., Shi, H.-S., Zhang, R.-X., Liu, J.-F., Ding, Z.-B., Lu, L., 2013. Glycine site N-methylD-aspartate receptor antagonist 7-CTKA produces rapid antidepressant-like effects in male rats. Journal of psychiatry \& neuroscience: JPN 38, 306. 


\section{Figure captions:}

Legend for Figure 1. Anatomical subdivisions of the prefrontal cortex of the rat. A) Lateral view of the rat's brain. Shaded areas are showing the PFC and its subregions. B) Coronal section through rostral telencephalon. Shaded areas showing the PFC and subregions. Abbreviations: aCg: Anterior Cingulate cortex, PL: Prelimbic cortex, IL: Infralimbic cortex.

Legend for Figure 2. Flowchart of the systematic review and meta-analysis

Legend for Figure 3. Forest Plot and results of the metanalysis with random-effects model. Showing the effects observed for each study (black squares) with its respective $95 \%$ confidence intervals (horizontal lines, CI) and the effect of the total metanalysis (diamond). Sample sizes may be found in table 2. Symbols located at the left side of the dotted line (representing the null effect) indicate interventions reducing the immobility time in the FST (antidepressant-like effect). In contrast, those at the right side indicate intervention increasing immobility time (stressor-like effect).

Legend for Figure 4. Funnel plot and Trim-and-fill analysis. Effect sizes (ES) calculated from the 63 studies (black dots) included in the original meta-analysis plotted against their errors yielded a slightly asymmetric funnel (black lines). Trim-and-fill analysis indicated 12 studies missing (blank circles) from original data in order to create symmetry in the funnel plot (shaded triangle). Non-adjusted combined effect size (black diamond) was towards the intervention side and statistically significant. Adjusted combined effect size (white diamond) was towards the intervention side, statistically significant but smaller than non-adjusted combined effect size.

Legend for Figure 5. Forest Plot and metanalysis result of the subgroup mPFC (medial prefrontal cortex) with the random-effects model. Showing the effects observed for each study (black squares) with their $95 \%$ confidence intervals (horizontal lines, $\mathrm{CI}$ ) and metanalysis stratified by interventions (activation, inhibition, unknown, black diamonds). Sample sizes may be found in table 2. Symbols located at the left side of the dotted line (representing the null effect) indicate interventions reducing the immobility time in the FST (antidepressant-like effect). In contrast, those at the right side indicate intervention increasing immobility time (stressor-like effect). 
Legend for Figure 6. Forest Plot and metanalysis result of the subgroup vmPFC (ventral medial prefrontal cortex) with random-effects model. Showing the effects observed for each study (black squares) with their 95\% confidence intervals (horizontal lines, CI) and metanalysis stratified by interventions (activation, inhibition, unknown, black diamonds). Sample sizes may be found in table 2. Symbols located at the left side of the dotted line (representing the null effect) indicate interventions reducing the immobility time in the FST (antidepressant-like effect). In contrast, those at the right side indicate intervention increasing immobility time (stressor-like effect).

Legend for Figure 7. Forest Plot and metanalysis result of the subgroup aCg (anterior cingulate cortex) with random-effects model. Showing the effects observed for each study (black squares) with their $95 \%$ confidence intervals (horizontal lines, CI) and metanalysis stratified by interventions (activation, inhibition, unknown, black diamonds). Sample sizes may be found in table 2. Symbols located at the left side of the dotted line (representing the null effect) indicate interventions reducing the immobility time in the FST (antidepressant-like effect). In contrast, those at the right side indicate intervention increasing immobility time (stressor-like effect).

Legend for Figure 8. Forest Plot and metanalysis result of the subgroup PL (pre limbic cortex) with random-effects model. Showing the effects observed for each study (black squares) with their 95\% confidence intervals (horizontal lines, CI) and metanalysis stratified by interventions (activation, inhibition, unknown, black diamonds). Sample sizes may be found in table 2. Symbols located at the left side of the dotted line (representing the null effect) indicate interventions reducing the immobility time in the FST (antidepressant-like effect). In contrast, those at the right side indicate intervention increasing immobility time (stressor-like effect).

Legend for Figure 9. Forest Plot and metanalysis result of the subgroup IL (infra limbic cortex) with random-effects model. Showing the effects observed for each study (black squares) with their 95\% confidence intervals (horizontal lines, CI) and metanalysis stratified by interventions (activation, inhibition, unknown, black diamonds). Sample sizes may be found in table 2. Symbols located at the left side of the dotted line (representing the null effect) indicate interventions reducing the immobility time in the FST (antidepressant-like effect). In contrast, those at the right side indicate intervention increasing immobility time (stressor-like effect). 
bioRxiv preprint doi: https://doi.org/10.1101/2021.04.27.441685; this version posted April 28, 2021. The copyright holder for this preprint (which

was not certified by peer review) is the author/funder, who has granted bioRxiv a license to display the preprint in perpetuity. It is made available under aCC-BY-NC-ND 4.0 International license.

Legend for Figure 10. Sensitivity analysis "leave-one-out" of the subgroup "Infralimbic inhibition". The bars represent the combined effect size (Hedges' g, left side) or heterogeneity ( $\mathrm{I}^{2}$, right side) calculated in the absence of the study mentioned in the respective line in the middle column. 


\section{Tables:}

Table 1 - Search strategy and selection of publications:

\begin{tabular}{|c|c|c|}
\hline Domain & Keywords & Selection criteria \\
\hline Behavioural test & $\begin{array}{l}\text { forced swimming test OR forced } \\
\text { swimming tests OR forced swimming } \\
\text { test, fst OR fst OR forced swim OR } \\
\text { Porsolt test OR Porsolt tests. }\end{array}$ & $\begin{array}{l}\text { Included studies published after } \\
1977 \text { reporting time or frequency } \\
\text { or scores of immobility in the } \\
\text { FST. Excluded studies that did } \\
\text { not evaluate immobility or } \\
\text { behaviour in the FST. }\end{array}$ \\
\hline Population & $\begin{array}{llcc}\text { "rodentia"[MeSH } & \text { Terms] } & \text { OR } \\
\text { mice[Tiab] } & \text { OR } & \text { mus[Tiab] } & \text { OR } \\
\text { mouse[Tiab] } & \text { OR } & \text { murine[Tiab] } & \text { OR } \\
\text { woodmouse[tiab] } & \text { OR } & \text { rats[Tiab] } & \text { OR } \\
\text { rat[Tiab] OR } & \text { murinae[Tiab] } & \text { OR } \\
\text { muridae[Tiab] } & \text { OR cottonrat[tiab] } & \text { OR } \\
\text { cottonrats[tiab] OR rodentia[Tiab] } & \text { OR } \\
\text { rodent[Tiab] OR } & \text { rodents[Tiab]. } & \end{array}$ & $\begin{array}{l}\text { Included studies in healthy rats. } \\
\text { Excluded studies using diseased } \\
\text { rats (as in experimental models } \\
\text { of pathologies) }\end{array}$ \\
\hline Brain region & $\begin{array}{l}\text { medial prefrontal cortex OR medial pre } \\
\text { frontal cortex OR medial PFC OR } \\
\text { mPFC OR infralimbic córtex OR } \\
\text { ventromedial pré-frontal cortex OR } \\
\text { ventromedial PFC OR vmPFC or } \\
\text { Cingulate cortex }\end{array}$ & $\begin{array}{l}\text { Included studies manipulating } \\
\text { the activity of the mPFC using } \\
\text { injections, electric stimulation, } \\
\text { etc before or during the } \\
\text { behavioural assessment in the } \\
\text { FST. Excluded studies observing } \\
\text { the activity of the mPFC after } \\
\text { systemic treatment or } \\
\text { behavioural testing. }\end{array}$ \\
\hline
\end{tabular}

Keywords used in the database search

Table 2: 
bioRxiv preprint doi: https://doi.org/10.1101/2021.04.27.441685; this version posted April 28, 2021. The copyright holder for this preprint (which was not certified by peer review) is the author/funder, who has granted bioRxiv a license to display the preprint in perpetuity. It is made available under aCC-BY-NC-ND 4.0 International license.

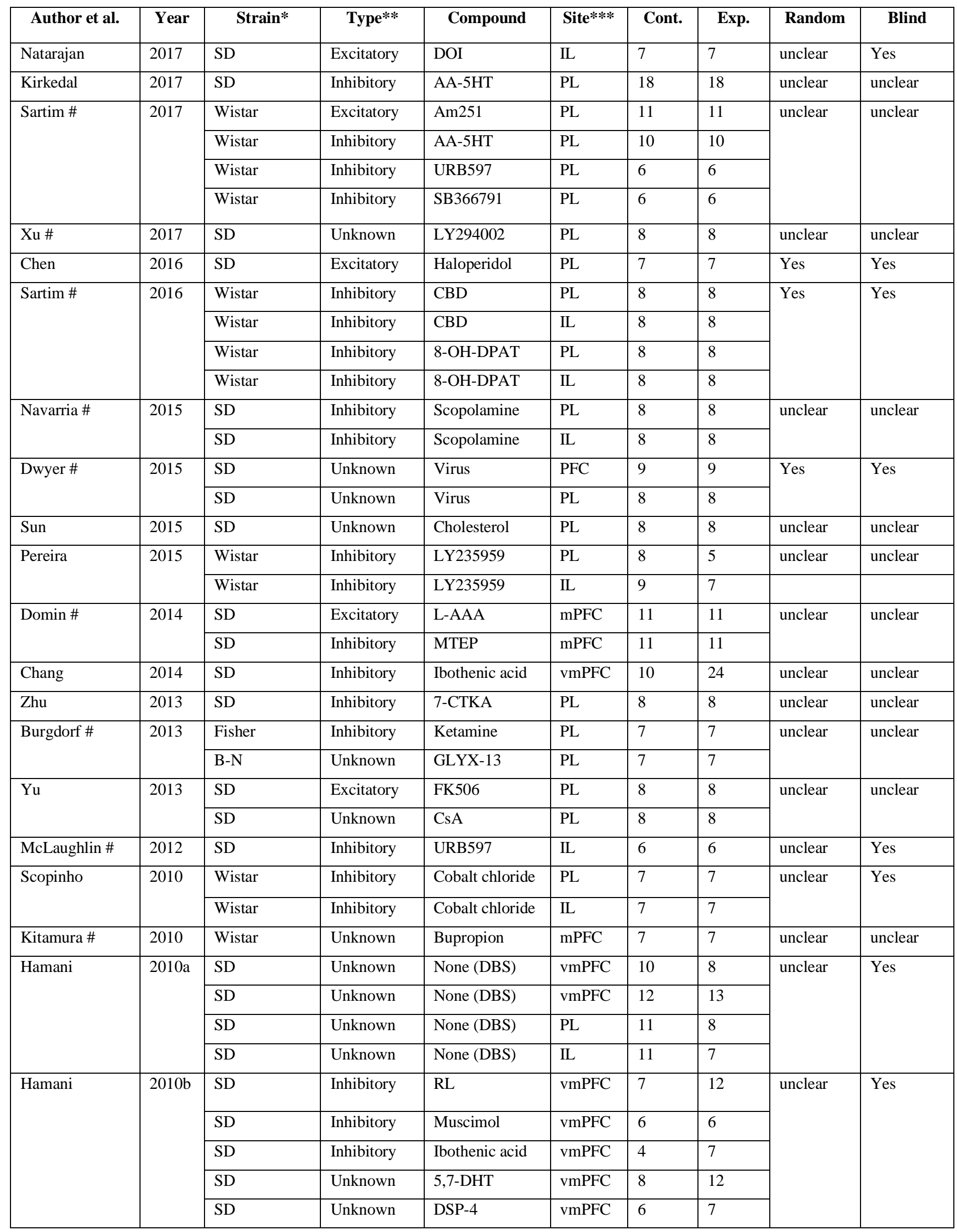


bioRxiv preprint doi: https://doi.org/10.1101/2021.04.27.441685; this version posted April 28, 2021. The copyright holder for this preprint (which was not certified by peer review) is the author/funder, who has granted bioRxiv a license to display the preprint in perpetuity. It is made available under aCC-BY-NC-ND 4.0 International license.

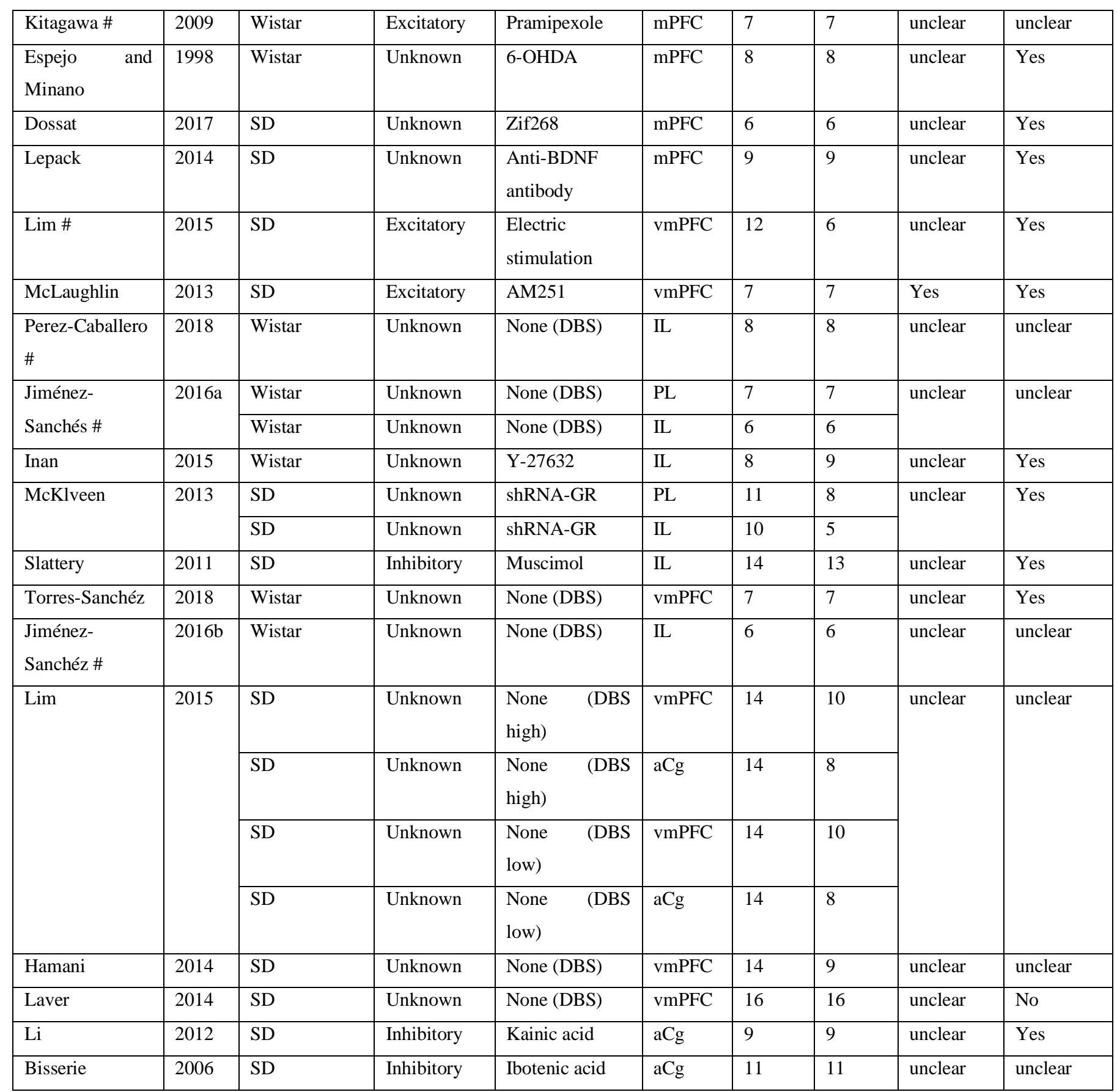

Abbreviations: aCg: anterior cingulate cortex B-N: Brown-Norway; DBS: deep brain stimulation; mPFC: medial prefrontal cortex, RL: Radiofrequency lesion; SD: Sprague-Dawley; \# indicates studies that did not report the exact number of animals per group; *all rats were male and adults; **types were defined by authors of primary studies; *** all studies reported bilateral injection or DBS, **** no study reported sample size calculation. 